\title{
Modeling of Crystalline Silicotitanate Ion Exchange Columns Using Experimental Data from SRS Simulated Waste
}

by

D. D. Walker

Westinghouse Savannah River Company

Savannah River Site

Aiken, South Carolina 29808

DOE Contract No. DE-AC09-96SR18500

This paper was prepared in connection with work done under the above contract number with the U.S.

Department of Energy. By acceptance of this paper, the publisher and/or recipient acknowledges the U. S. Government's right to retain a nonexclusive, royalty-free license in and to any copyright covering this paper, along with the right to reproduce and to authorize others to reproduce all or part of the copyrighted paper. 


\section{DISCLAIMER}

This report was prepared as an account of work sponsored by an agency of the United States Government. Neither the United States Government nor any agency thereof, nor any of their employees, makes any warranty, express or implied, or assumes any legal liability or responsibility for the accuracy, completeness, or usefulness of any information, apparatus, product, or process disclosed, or represents that its use would not infringe privately owned rights. Reference herein to any specific commercial product, process, or service by trade name, trademark, manufacturer, or otherwise does not necessarily constitute or imply its endorsement, recommendation, or favoring by the United States Government or any agency thereof. The views and opinions of authors expressed herein do not necessarily state or reflect those of the United States Government or any agency thereof.

This report has been reproduced directly from the best available copy.

Available to DOE and DOE contractors from the Office of Scientific and Technical Information, P. O. Box 62, Oak Ridge, TN 37831; prices available from (423) 576-8401.

Available to the public from the National Technical Information Service, U. S. Department of Commerce, 5285. Port Royal Road, Springfield, VA 22161. 


\section{DISCLAIMER}

Portions of this document may be illegible in electronic image products. Images are produced from the best available original document. 
WSRC-TR-98-00396, Rev. 0

Keywords: Salt processing, High level waste

Retention: Permanent

MODELING OF CRYSTALLINE SILICOTITANATE ION EXCHANGE COLUMNS USING EXPERIMENTAL DATA FROM SIMULATED SRS WASTE

D. D. Walker

Publication Date: January 6, 1999

Westinghouse Savannah River Company

Savannah River Technology Center

A iken, SC 29808

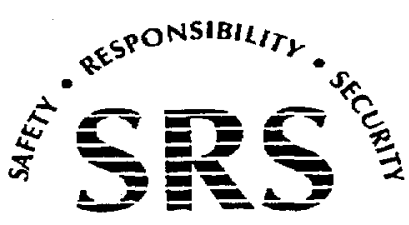




\section{Modeling of Crystalline Silicotitanate Ion Exchange Columns}

Using Experimental Data from SRS Simulated Waste

\section{Author}

$\frac{\text { Aarel }}{\text { D. D. Walker, Waste Processing Technology }} \frac{1 / 6 / 99}{}$

\section{Approvals}

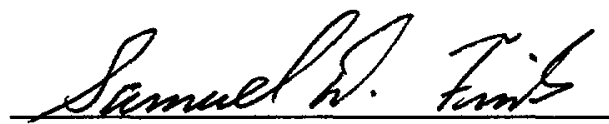

S. D. Fink, Level 4 Manager

$$
1-6-99
$$

Waste Processing Technology

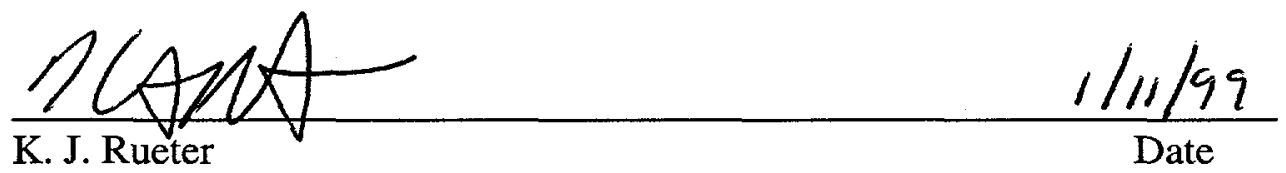

Salt Disposition Systems Engineering Team

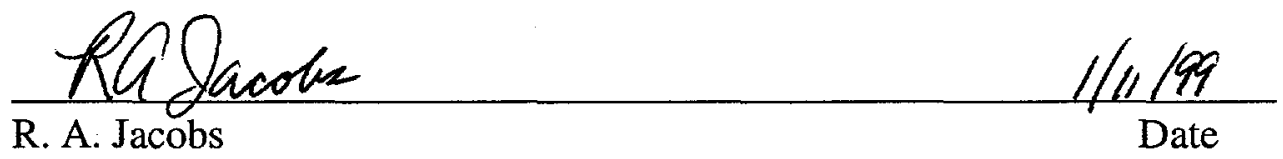

In-Tank Precipitation Flow Sheet Team

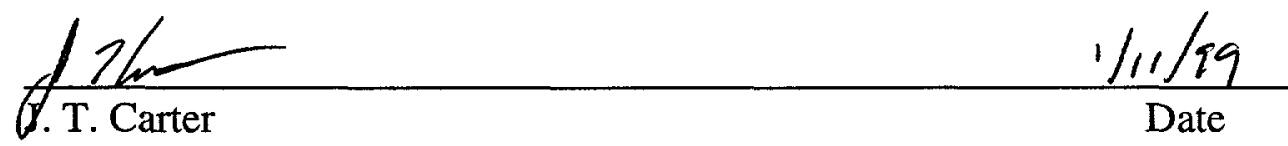

In-Tank Precipitation Flow Sheet Team Leader

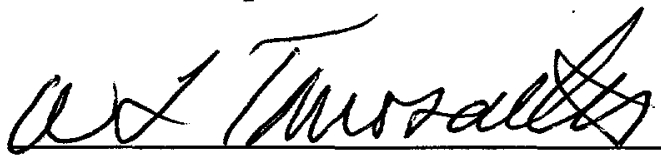

W. L. Tamosaitis, Level 3 Manager

Date

Waste Processing Technology 


\section{CONTENTS}

SUMMARY AND DISCUSSION .........................................................

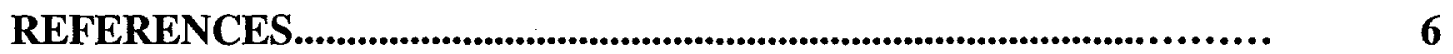

APPENDIX A: Purdue Report.................................................... 7

APPENDIX B: Texas A\&M Report................................................. 29 


\title{
MODELING OF CRYSTALLINE SILICOTITANATE ION EXCHANGE COLUMNS USING EXPERIMENTAL DATA FROM SIMULATED SRS WASTE
}

\author{
By D. D. Walker
}

\section{SUMMARY AND DISCUSSION}

Non-elutable ion exchange using crystalline silicotitanate is being considered for removing cesium from Savannah River Site (SRS) radioactive waste. ${ }^{1}$ The construction cost of this process depends strongly on the size of the ion exchange column required to meet product specifications. To validate locally developed column sizing calculations, SRS subcontracted two renowned experts in this field to perform similar calculations: Professor R. G. Anthony (Department of Chemical Engineering, Texas A\&M University) and Professor N.-H. Wang (School of Chemical Engineering, Purdue University). The results of their calculations of column size and performance reported previously ${ }^{2}$ closely agree and provided a basis for preliminary design of a salt decontamination process.

The previous calculations used cesium adsorption isotherms calculated by R. A. Jacobs ${ }^{3}$ and mass transfer parameters derived from previous work. ${ }^{2}$ New equilibrium adsorption and column performance data for CST in simulated SRS waste were reported following the initial column sizing calculations. ${ }^{4}$ The new equilibrium adsorption data indicate greater capacity than previously calculated (i.e., use of the $30 \%$ dilution factor underestimates capacity). Column performance was modeled by both groups using a single set of values for diffusivity and column capacity. The largest discrepancies between experiment and model occurred in the highest flow rate column test. The discrepancies reflect uncertainty in the values for particle capacity or intraparticle diffusivity, or in the mass transfer mechanism in the model. Nevertheless, the column lengths in the previous report equal or exceed the column lengths derived from the new data. Based on the more recent work, the author recommends the following.

- Retain the conservative column size from the original calculations in the proposed design at this time and reduce at a later time following additional experiments and calculations that improve the reliability of the estimate.

- Conduct additional column experiments to understand the reproducibility of the results, the capacity of the resin, and the kinetics.

- Evaluate the need to enhance the mass transfer detail in the existing models. 
The two modeling groups analyzed the new data to refine their previous calculations. The appendices contain copies of the reports from the two modeling groups. The following summarize the results from the new calculations.

- Both modeling groups recommended $20-30 \%$ shorter columns.

- The shorter columns result primarily from increased estimates of the diffusivity.

- The Texas A\&M group reproduced the fast column test results by decreasing the CST capacity by $30 \%$.

- In this fit, the diffusivity was the same as used with the slower column tests and the predicted column length was shorter.

- Increasing the diffusivity improves the fit but not as much as lowering the capacity.

- The new equilibrium adsorption data $\left(\mathrm{K}_{\mathrm{d}} \mathrm{s}\right)$ indicating a dilution factor of 1.0 between powdered CST and the engineered form of CST do not significantly impact column size.

- Although higher $\mathrm{K}_{\mathrm{d}} \mathrm{s}$ do not decrease column size (i.e., the mass transfer zone length does not change), they imply increased cesium loading, less frequent column change-outs, and decreased CST usage.

- Higher cesium loading increases the radiation from the column and the rates of radiolytic gas generation and heat production.

Because of the uncertainties in the interpretation of the test data, design efforts should continue to use the column sizes from the previous report ${ }^{2}$ since they provide a conservative design until improved understanding of CST capacity and kinetics is obtained. However, the new test results and column sizing calculations do not suggest larger columns are required.

There are several possible explanations for the lack of agreement between the model predictions and the fast column test results. Experimental and analytical uncertainties may account for some or all of the discrepancy. These uncertainties include inaccuracies in the concentration measurements, wall effects in the small diameter column, termination of the column run before complete loading, differences in the simulated waste solutions, and differences in conditioning of the CST. Many of these can reduce the apparent capacity of the CST. Alternatively, CST mass transfer kinetics may be more complicated than currently modeled. Both models assume instantaneous equilibrium within the pores of the engineered form of the resin. For slow adsorption kinetics (as suggested by the length of time required to reach equilibrium in $\mathrm{K}_{\mathrm{d}}$ tests), an additional mass transfer resistance may exist. Researchers from Purdue suggest two possibilities: non-equilibrium behavior (i.e., the intrinsic adsorption rate is relatively slow compared to convection and diffusion rates), or slow surface diffusion (i.e., the diffusion mechanism includes pore and surface diffusion, with the surface diffusion coefficient much larger than the pore diffusion coefficient). With additional effort, both mechanisms could be included in the model. An alternative suggested by Texas A\&M researchers is increased 
intracrystalline resistance to diffusion as particles saturate with cesium. In this case, modeling would use a solid-state diffusivity that decreases as loading increases.

Resolution of this issue will require additional column tests.

This work results from a request from P. L. Rutland, Technical Task Request, "CST Ion Exchange - Salt Team Phase 3 Evaluation," \#HLE-TAR-98060, July 14, 1998.

\section{REFERENCES}

1. P. L. Rutland et al., "Bases, Assumptions, and Results of the Flowsheet Calculations for the Initial Eighteen Salt Disposition Alternatives", WSRC-RP-98-00166, 25 June 1998.

2. D. D. Walker, "Modeling of Crystalline Silicotitanate Ion Exchange Columns," WSRC-TR-98-00343, Rev.0, October 2, 1998.

3. R. A. Jacobs, "Powdered Crystalline Silicotitanate (CST) Isotherms for SRS Wastes (U)," WSRC-RP-98-01051, Rev.0, September 11, 1998.

4. D. D. Walker, W. D. King, D. P. Diprete, L. L. Tovo, D. T. Hobbs, and W. R. Wilmarth, "Cesium Removal from Simulated SRS High-Level Waste using Crystalline Silicotitanate," WSRC-TR-98-00344, Rev.1, October 16, 1998. 


\title{
APPENDIX A
}

\author{
Design of a Carousel Process for Removing Cesium from SRS Waste Using Crystalline Silicotitanate Ion \\ Exchanger
}

\author{
Benjamin J. Hritzko and N.-H. Linda Wang \\ School of Chemical Engineering, Purdue University, West Lafayette, IN 47907-1283 \\ D. Douglas Walker \\ Westinghouse Savannah River Company, Aiken, SC 29808
}

\begin{abstract}
Designs of a three-column carousel process based on crystalline silicotitanate (CST) ion exchanger have been developed for removing radioactive ${ }^{137} \mathrm{Cs}^{+}$from Savannah River Site's (SRS) nuclear wastes. A multicomponent ion exchange equilibrium model (Zheng et al., 1997) from Texas A\&M University, which is based on batch data obtained from CST powder, is used to generate cesium loading data at different cesium concentrations for various types of SRS wastes. These loading data are fit to the Langmuir equation to obtain effective single-component cesium isotherm parameters. The predictions are in reasonable agreement with batch test data obtained from CST powder, an early CST pellet batch (38B), and a later batch (IE911) using two SRS waste simulants. The ratios between experimental cesium distribution coefficients and predicted values are between 0.56 and 1.0. The variation appears to be due to inadequate equilibration time in some of the batches. Mass transfer parameters are estimated by analyzing column data of a simulated SRS waste and Melton Valley Storage Tank W29 (MVST-W29) waste. The intraparticle diffusivity estimated for the two wastes can be well correlated by means of the Stokes-Einstein equation.

Simulations are performed to determine the length of the mass transfer zone for given feed compositions, $\mathrm{Cs}^{+}$ concentrations, and linear velocities. In order to ensure high column utilization during both the transient and cyclic steady state periods, the length of a single segment in the carousel process is chosen to be the mass transfer zone length after the concentration wave achieves a constant pattern. Analysis of the dimensionless groups in the differential mass balance equations reveals that the normalized mass transfer zone length is linearly proportional to the particle Peclet number. The proportionality constant is a function of the waste composition and the $\mathrm{Cs}^{+}$concentration in the waste. The higher the effective $\mathrm{Cs}^{+}$capacity and the higher the $\mathrm{Cs}^{+}$concentration, the smaller the proportionality constant. This dimensionless group analysis allows one to easily adjust designs for variations in particle size, linear velocity, and intraparticle diffusivity.
\end{abstract}

\section{Introduction}

Over 100 million gallons of radioactive waste, generated by nuclear reactors and weapon production plants, is now in underground storage tanks (USTs) at Department of Energy (DOE) sites in Hanford, Savannah River, Oak Ridge, Idaho, and Fernald (McGinnis et al., 1995). The cost of treating this waste using current technologies is estimated at 100 billion dollars (McGinnis et al., 1995). After the initial treatment, the waste in its final form is vitrified in borosilicate glass for permanent storage.

Several different approaches are currently under investigation for treating the supernatant before it is placed in long-term storage (McGinnis et al., 1995). The present study is focused on CST ion exchange for treatment of Savannah River Site (SRS) wastes. CST has a high affinity for the major radioactive contaminant ${ }^{137} \mathrm{Cs}^{+}$. Since the affinity is high, a large amount of ${ }^{137} \mathrm{Cs}^{+}$can be confined within a small volume of saturated CST particles. Since the cost of making glass canisters is expected to be quite high, it is important to utilize the CST exchanger as much as possible. A continuous carousel process with three packed columns in series (Figure 1) is proposed. The carousel design allows the cesium level in the decontaminated waste to be below the required levels (less than $1.3 \times 10^{-3} \mathrm{mg} / \mathrm{L}$ $\mathrm{Cs}^{+}$) and almost full utilization of the adsorbent (Ernest et al., 1997).

CST ion exchanger was developed at Texas Al\&M University (TAMU) in a powder form (Anthony et al., 1993; Anthony et al., 1994) and was engineered into a pellet form by UOP. The pellet form is the CST powder mixed with an inert binder. This binder makes CST feasible for column applications, but it is expected to give the pellets a lower effective capacity per unit weight than the powder (McCabe, 1995; McCabe, 1997). Zheng et al. (1997) at TAMU developed a detailed multicomponent ion exchange model that describes the uptake of $\mathrm{Cs}^{+}$on CST powder in the presence of competing ions. They validated the model via batch experiments conducted using waste simulants in which $\mathrm{Cs}^{+}$loading on CST powder was measured (Zheng et al., 1997). 


\section{APPENDIX A (continued)}

In this work, the equilibrium uptakes of $\mathrm{Cs}^{+}$on CST powder predicted from the TAMU model have been fit to a single-component Langmuir isotherm for six different SRS waste compositions. The batch test data obtained for CST pellets (38B and IE911) can be explained by a dilution factor of 0.56 to 1.0. This approach yields effective $\mathrm{Cs}^{+}$ isotherms, which are needed in a dynamic column model for the carousel design.

Mass transfer parameters are estimated by analyzing breakthrough data of an SRS waste simulant, as well as data from Cesium Removal Demonstration (CsRD) column experiments and CsRD support column experiments from Oak Ridge National Laboratory (ORNL). The CsRD experiments were performed on CST pellets from the same lot and with the same feed (Melton Valley Storage Tank W29, or MVST-W29) over a wide range of linear superficial velocities $(0.3$ to $10.8 \mathrm{~cm} / \mathrm{min})$. Porous column model simulations are compared to the column data and the effective intraparticle diffusivities $\left(D_{p}\right)$ are determined for the SRS waste simulant and the MVST-W29 waste. The StokesEinstein equation is shown to correlate the values of $D_{p}$ for the two different wastes, based on the viscosities of the wastes. For both feeds the model yields a close fit to the column data. The ORNL 50 percent breakthrough times can be well predicted using the TAMU model with a dilution factor from 0.56 to 0.66 . The SRS column data can be well explained by the TAMU model with a dilution factor of 1.0 .

The model and mass transfer parameters are used in simulations to obtain carousel designs for treating largescale SRS waste. The length of the mass transfer zone determines the column length requirement for the segments in a carousel process. The mass transfer zone is defined as the length of column required to contain the $\mathrm{Cs}^{+}$concentration wave from 90 percent of the feed concentration to $1.3 \times 10^{-3} \mathrm{mg} / \mathrm{L}$. An analysis of the dimensionless groups in the model has shown that the mass transfer zone length (normalized by the particle radius) depends only on the particle Peclet number. The proportionality constant in this relationship is a function of the $\mathrm{Cs}^{+}$concentration and the effective $\mathrm{Cs}^{+}$isotherm parameters, which depend on the waste compositions. Using this linear relation, one can easily determine the carousel column size at a given linear velocity, particle size, and intraparticle diffusivity.

This study establishes a model-based design approach that is efficient and requires relatively few experiments. This approach gives carousel designs with high column utilization both during startup and at cyclic steady state. This method can be applied to design carousel ion exchange processes for other complex wastes.

\section{Simulation Models, Parameters, and Assumptions}

The mathematical model utilized in the simulations is a porous model which takes into account competitive adsorption, bulk convection, axial dispersion, film mass transfer, and pore diffusion. Since surface diffusion effects are not evident from the available data, the pore diffusion model is used in this analysis. The numerical solutions of the governing equations and boundary conditions are performed by the VERSE simulation package (Berninger et al., 1997; Whitley, 1990). This model has been validated in many previous studies (Ernest et al., 1997; Koh et al., 1998; Ma et al., 1996). The pore diffusion model assumes uniform spherical adsorbent particles, plug flow with constant linear velocity, local equilibrium within the adsorbent and constant diffusivities.

\section{Pore diffusion model}

In the pore diffusion model, the material balance in the mobile phase is given by

$$
\begin{aligned}
& \frac{\partial C}{\partial t}=E_{b} \frac{\partial^{2} C}{\partial z^{2}}-u_{0} \frac{\partial C}{\partial z}-\frac{3 k_{f}\left(1-\varepsilon_{b}\right)}{R_{p} \varepsilon_{b}}\left(C-C_{p, r=R_{p}}\right) \\
& z=0, \quad E_{b} \frac{\partial C}{\partial z}=u_{0}\left(C(t, 0)-C_{0}\right) \\
& z=L, \quad \frac{\partial C}{\partial z}=0 \\
& t=0, \quad C=C(0, z)
\end{aligned}
$$

where $C$ is the mobile phase concentration $(\mathrm{mg} / \mathrm{mL}), t$ is time $(\mathrm{min}), E_{b}$ is the axial dispersion coefficient $\left(\mathrm{cm}^{2} / \mathrm{min}\right), z$ is the axial distance along the column $(\mathrm{cm}), u_{0}$ is the mobile phase velocity $(\mathrm{cm} / \mathrm{min}), k_{f}$ is the film mass transfer coefficient ( $\mathrm{cm} / \mathrm{min}), R_{p}$ is the particle radius $(\mathrm{cm})$, and $C_{p, r=R p}$ is the particle phase solute concentration at the surface $(\mathrm{mg} / \mathrm{mL})$. In the pore phase, the material balance equation is 


\section{APPENDIX A (continued)}

$$
\begin{gathered}
\left(\varepsilon_{p}+\left(1-\varepsilon_{p}\right) \frac{\partial q}{\partial C_{p}}\right) \frac{\partial C_{p}}{\partial t}=\varepsilon_{p} \frac{D_{p}}{r^{2}} \frac{\partial}{\partial r}\left(r^{2} \frac{\partial C_{p}}{\partial r}\right) \\
r=0, \quad \frac{\partial C_{p}}{\partial r}=0 \\
r=R_{p}, \quad e_{p} D_{p} \frac{\partial C_{p}}{\partial r}=k_{f} R_{p}\left(C-C_{p, r=R_{p}}\right) \\
t=0, \quad C_{p}=C_{p}(0, r)
\end{gathered}
$$

where $C_{p}$ is the pore-phase concentration $(\mathrm{mg} / \mathrm{mL}), q$ is the solid-phase concentration $(\mathrm{mg} / \mathrm{mL} \mathrm{S.V.)}, r$ is the distance in the radial direction $(\mathrm{cm})$, and $D_{p}$ is the intraparticle diffusivity $\left(\mathrm{cm}^{2} / \mathrm{min}\right)$.

Eqs. 1 and 2 and their boundary conditions can be rewritten as follows in terms of the dimensionless quantities listed in Table 1.

$$
\begin{aligned}
& \frac{\partial C}{\partial \theta}=\frac{1}{\mathrm{Pe}_{b}} \frac{\partial^{2} C}{\partial x^{2}}-\frac{\partial C}{\partial x}-3 L_{c}^{*} \phi_{b} k_{f}^{*}\left(C-C_{p, \xi=1}\right) \\
& x=0, \quad \frac{\partial C}{\partial x}=P e_{b}\left(C-C_{0}(\theta)\right) \\
& x=1, \quad \frac{\partial C}{\partial x}=0 \\
& \theta=0, \quad C=C(0, x) \\
&\left(1+\phi_{p} \frac{\partial q}{\partial C_{p}}\right) \frac{\partial C_{p}}{\partial \theta}=L_{c}^{*} \frac{1}{\mathrm{Pe}_{p}} \frac{1}{\xi^{2}} \frac{\partial}{\partial \xi}\left(\xi^{2} \frac{\partial C_{p}}{\partial \xi}\right) \\
& \xi=0, \quad \frac{\partial C_{p}}{\partial \xi}=0 \\
& \xi=1, \quad \frac{\partial C_{p}}{\partial \xi}=\frac{1}{1+\phi_{p}} P e_{p} k_{f}^{*}\left(C-C_{p}\right) \\
& \theta=0, \quad C_{p}=C_{p}(0, \xi)
\end{aligned}
$$

\section{Effective $\mathrm{Cs}^{+}$isotherm approach for complex wastes}

Figure 2 shows effective $\mathrm{Cs}^{+} / \mathrm{CST}$ isotherms based on TAMU model predictions for the various SRS wastes. The compositions of the SRS wastes are listed in Table 2. Figure 3 shows the TAMU model predictions for the SRS standard simulant and the batch test data for CST powder (McCabe, 1995) and CST pellets (McCabe, 1997). The experimental data are in reasonable agreement with the model predictions. The waste is a complex multicomponent mixture and the TAMU model (Zheng et al., 1997) is able to predict to within \pm 20 percent the effective adsorption capacity of $\mathrm{Cs}^{+}$at various feed $\mathrm{Cs}^{+}$concentrations for the SRS standard simulant. In the simulations, a simple Langmuir isotherm is chosen to describe the equilibrium uptake of $\mathrm{Cs}^{+}$on CST. TAMU model isotherms are fit to individual Langmuir isotherms. For the W29 waste, it is necessary to multiply the Langmuir coefficient $a$ by a dilution factor. This factor has been justified in two separate instances. Figure 3a shows experimental batch data for powdered CST (DG-112) and batch data for the engineered form (38B), both in SRS standard simulant. The maximum capacity (at high concentration) of the engineered form is 56 percent of that of the powdered form. At low concentrations, the dilution factor is between 0.7 and 1.0. The solid line shows that the TAMU model can predict $\mathrm{Cs}^{+}$uptake on the powdered CST reasonably well. The uptake of $\mathrm{Cs}^{+}$on the engineered form is in reasonable agreement with the TAMU model prediction multiplied by dilution factors of 0.56 and 0.7 (dashed lines in Figure 3). This lower dilution factor for the pellet at high $\mathrm{Cs}^{+}$concentration could be due to nonequilibrium data, since the samples in the batch tests were taken at 48 hours. This hypothesis is supported by batch test data obtained by Hunt et al. (1998) shown in Figure 3b. The batch data collected at 24 and 72 hours are not at equilibrium, evident from time-varying concentration. For these large particles, the equilibration time should be 168 hours or more. In a second case, shown in Figure 4, the TAMU model 


\section{APPENDIX A (continued)}

for $\mathrm{Cs}^{+}$uptake on powdered CST in the MVST-29 waste is denoted by a solid line. The two dotted lines show the bestfit Langmuir isotherms to column data performed on IE911 with the MVST-W29 waste. All of the column data are well predicted by isotherm parameters within this range. The maximum capacities determined from these two isotherms (on engineered CST) are 56 percent and 66 percent of that of the powdered form CST. This low dilution factor could be due to the following factors: a combination of the presence of an inert binder, TAMU model inaccuracy, or the presence of competing ions in the real waste (such as $\mathrm{Zn}, \mathrm{Pb}$, and $\mathrm{Ba}$ ) that are not considered in the TAMU model. Table 3 lists the Langmuir isotherm parameters for W29 and various SRS wastes.

\section{Mass transfer parameters}

Melton Valley Storage Tank W29 Column Tests. The Brownian diffusivity for W29 is taken from the work of Ernest et al. (1997). The Brownian diffusivity for the SRS wastes is assumed to be 73 percent of that for W29, according to the Stokes-Einstein equation (Eq. 5 below). The film mass transfer coefficient, $k_{f}$, is calculated from the correlation by Wilson and Geankoplis (1966) and the axial dispersion coefficient, $E_{b}$, is calculated from the correlation by Chung and Wen (1968). These parameters are used to analyze ORNL CST small-scale (10 mL) column data (Lee et al., 1997) and large-scale (38 L) column data (J. F. Walker et al., 1998). Simulation results are compared to the experimental data. It is found that the breakthrough times are well predicted when the isotherm parameters for W29 from the TAMU model are adjusted by a factor of 0.56 to 0.66 , indicating the effective $\mathrm{Cs}^{+}$isotherm approach is successful in predicting $\mathrm{Cs}$ breakthrough in a complex mixture. The intraparticle diffusivity, $D_{p}$, is then fit to the smallscale frontal data. Figures $5 a-c$ show the comparison of experimental data to simulation results for small scale CsRD support runs by $D$. D. Lee. These parameters were then used to predict the large-scale frontal data, and it was found that the large-scale breakthrough curves were slightly more spread than predicted. Figures 6 and 7 show the comparison of experiment to simulation for large scale CsRD column experiments. This indicates that dispersion in the large columns is greater than in small columns, perhaps as a result of different packing procedures.

Westinghouse Savannah River Company Column Tests. Since MVST waste has a viscosity of $1.6 \mathrm{cp}$ and SRS waste has a viscosity of $2.2 \mathrm{cp}$, the value of $D_{p}$ determined from the CsRD column tests is not valid for designing columns to handle SRS waste. According to the Stokes-Einstein equation, the diffusivity is related to the solution viscosity:

$$
D=\frac{k_{B} T}{6 \pi \mu R_{0}}
$$

where $D$ is the diffusivity, $k_{B}$ is Boltzmann's constant, $T$ is absolute temperature, $\mu$ is the viscosity, and $R_{0}$ is the solute radius. The value of the diffusivity is inversely proportional to the fluid viscosity, so that the intraparticle diffusivity for SRS wastes is estimated to be

$$
1.0 \times 10^{-4}\left(\frac{1.6}{2.2}\right)=7.3 \times 10^{-5} \mathrm{~cm}^{2} / \mathrm{min}
$$

Preliminary column data are obtained for SRS average waste on CST pellets (D. D. Walker et al., 1998). The column experiments can be well predicted assuming a dilution factor of 1.0 and a $D_{p}$ of $7.3 \times 10^{-5} \mathrm{~cm}^{2} / \mathrm{min}$ (Eq. 6). Figure 8 shows column effluent histories for three runs in a laboratory-scale column $(17.7 \mathrm{~mL})$ at three different linear superficial velocities $\left(u_{s}=0.27,0.98\right.$, and $\left.4.1 \mathrm{~cm} / \mathrm{min}\right)$. Flow rate and $\mathrm{Cs}^{+}$feed concentration are taken into account in the model. The positions and shapes of the breakthrough curves are well predicted by the model. The isotherm parameters, mass transfer model and the correlation of $D_{p}$ using the Stokes-Einstein equation appears to be valid.

\section{Column parameters}

The particle size, interparticle void fraction $\left(\varepsilon_{b}\right)$, and intraparticle void fraction $\left(\varepsilon_{p}\right)$ were based on the known densities of the CST particles (Anthony, 1998). In the mathematical model, it is assumed that all the particles are spherical and of uniform size ( $375 \mu \mathrm{m}$ in diameter). Table 4 lists the simulation parameters. These mass transfer and system parameters have been employed to design large-scale carousel processes for treating SRS wastes. 


\title{
APPENDIX A (continued)
}

\author{
Design Approach
}

\section{Determination of constant-pattern mass transfer zone length}

The first step in the design is to determine the mass transfer zone length, which is a function of the isotherm parameters, $\mathrm{Cs}^{+}$feed concentrations, mass transfer parameters, and linear velocity. The mass transfer zone length is examined at two different flow rates-15 and $25 \mathrm{gpm}$, which correspond to two different superficial velocities ( 4.9 and $8.1 \mathrm{~cm} / \mathrm{min}$, respectively). Since the isotherm is nonlinear at the concentration level in the SRS waste (Figure 2), the concentration waves eventually develop into a constant pattern. A sufficiently long column ( $66 \mathrm{ft}$ ) is chosen in this simulation so that the waves can reach a constant pattern. Figures $9 \mathrm{a}-\mathrm{b}$ demonstrate the mass transfer zone length determination. The length of the mass transfer zone is determined from the concentration profile where the local concentration decreases from 90 percent of the feed concentration to $1.3 \times 10^{-3} \mathrm{mg} / \mathrm{L}$. The feed compositions are listed in Table 2. Notice that the concentration of $\mathrm{Cs}^{+}$varies from waste to waste. For this specification, the percent saturation in the lead column is much higher than 90 percent (the target for large-scale applications). Clearly, the mass transfer zone length, $L_{\mathrm{MTZ}}$, increases on increasing column length and reaches a maximum value when a constant pattern develops.

If one chooses the constant pattern $L_{\mathrm{MTZ}}$, the carousel design is straightforward. A three-segment carousel will have a total length of $3 L_{\mathrm{MTZ}}$. The choice of constant pattern $L_{\mathrm{MTZ}}$ to be the column length will ensure that when the carousel operation reaches cyclic steady state, the percent sorbent utilization in the lead column (saturation zone) will satisfy the 90 percent or higher utilization desired. VERSE simulations confirm this. An example is shown in Figure 11.

\section{Case 1: Carousel designs for a fixed column diameter}

For practical applications, a column diameter of about $4 \mathrm{ft}$ and a segment length of $16 \mathrm{ft}$ or smaller are desired. Table 5 lists the column length requirements for the six SRS feeds when the column diameter is fixed at $4 \mathrm{ft}$. For each isotherm, we have determined the mass transfer zone length for two flow rates (15 gpm and $25 \mathrm{gpm}$ ).

\section{Dimensionless group analysis}

By examining the differential mass balance equations and boundary conditions, Eqs. 3 and 4, one expects that the concentration profile or dimensionless mass transfer zone length, $L_{\mathrm{MTZ}}{ }^{*}$, at constant pattern is a function of the dimensionless groups of the equations $\left(L_{c}^{*}, k_{f}^{*}, \phi_{b}, \phi_{p}, \mathrm{Pe}_{p}\right.$, and $\left.\mathrm{Pe}_{b}\right)$, the isotherm parameters, and the feed $\mathrm{Cs}^{+}$ concentration. For a sufficiently long column $\left(L_{c} / R_{p}>1000\right)$ at a relatively high linear velocity $\left.u_{0}>0.25 \mathrm{~cm} / \mathrm{min}\right)$, $L_{\mathrm{MTZ}}{ }^{*}$ is controlled by intraparticle diffusion. Therefore, $L_{\mathrm{MTZ}}{ }^{*}$ is only a function of $\mathrm{Pe}_{p}$ for a given waste. This relationship can be summarized as:

$$
L_{\mathrm{MTZ}}^{*} \propto \mathrm{Pe}_{p}
$$

where

$$
L_{\mathrm{MTZ}}^{*} \equiv \frac{L_{\mathrm{MTZ}}}{R_{p}}
$$

is the dimensionless mass transfer zone length. Eq. 7 states that the length of the mass transfer zone is directly proportional to the linear velocity and the square of the particle radius and that it is inversely proportional to the intraparticle diffusivity. Figure 10 shows the relationship between the dimensionless mass transfer zone and the Peclet number. It should be pointed out that the slope of the line in each case depends on both the waste type and the cesium concentration. If the waste composition remains the same as those in Table 2, Figure 10 provides a convenient estimate of $L_{\mathrm{MTZ}}$ (or carousel size) when $R_{p}, D_{p}$, or $u_{0}$ is varied.

Two important trends are apparent from Figure 10. First, for a given $\mathrm{Cs}^{+}$concentration, $L_{\mathrm{MTz}}{ }^{*}$ decreases with increasing Langmuir $a$ value. One can see in Figure 10 that for the bounding cases, in which the $\mathrm{Cs}^{+}$concentration is $0.0007 \mathrm{M}, L_{\mathrm{MTZ}}$ * is highest for the "High $\mathrm{NO}_{3}-\mathrm{b}$ " case and lowest for the "High OH-b" case for all values of $\mathrm{Pe}_{p}$. Recall from Table 3 that the "High $\mathrm{NO}_{3}-b$ " case has the lowest Langmuir $a$ value and the "High $\mathrm{OH}-b$ " case has the highest $a$ value among the three bounding cases. Second, for a given isotherm, a higher $\mathrm{Cs}^{+}$concentration leads to a lower $L_{\mathrm{MTZ}}$. This can be seen in the "High $\mathrm{NO}_{3}-\mathrm{b}$ " case, which has the lowest Langmuir $a$ value among the six wastes 


\section{APPENDIX A (continued)}

but has a lower $L_{\mathrm{MTZ}}$ " than the nominal cases because its $\mathrm{Cs}^{+}$concentration is 1.9 times higher than the "High $\mathrm{OH}^{\circ}$ case and five times higher than the "Average" and "High $\mathrm{NO}_{3}$ " cases.

\section{Case 2: Carousel designs for a fixed column length}

For the six different types of SRS wastes, the segment lengths (or $L_{\mathrm{MTZ}}$ ) are less than $16 \mathrm{ft}$ with two exceptions, the 25 gpm cases for the "Average Waste" and the "High $\mathrm{NO}_{3}$ Waste" (Table 5). For these two cases and the other wastes, we investigate the designs with a fixed segment length of $16 \mathrm{ft}$ and a diameter that is either larger or smaller than $4 \mathrm{ft}$. The results are reported in Table 6 . When the segment length is fixed at $16 \mathrm{ft}$, this implies that $L_{\mathrm{MTZ}}$ is fixed at $16 \mathrm{ft}$ for all the different feeds, whereas the linear velocity $u_{0}$ is varied to achieve this goal. The $u_{0}$ values are determined by finding the Peclet number that gives $L_{\mathrm{MTZ}}=16 \mathrm{ft}$. Column diameters that can handle $15 \mathrm{gpm}$ and 25 gpm are calculated according to a given $u_{0}$. Notice that for a given feed, the linear velocity is the same for 15 and 25 gpm. A change in the column diameter allows for a change in the volumetric flow rate.

As clearly shown in Table 5, the $L_{\mathrm{MTZ}}$ for 4 -ft diameter columns for some cases are less than $16 \mathrm{ft}$. Therefore the column diameter in Table 6 can be reduced to below $4 \mathrm{ft}$ and a higher $u_{0}$ can be used. In contrast, for the cases in Table 5 where the $L_{\mathrm{MTZ}}$ are longer than $16 \mathrm{ft}$, a lower $u_{0}$ must be used to confine the mass transfer zone to $16 \mathrm{ft}$, and column diameters must be increased to above $4 \mathrm{ft}$ to accommodate $15 \mathrm{gpm}$ and $25 \mathrm{gpm}$ feed flow rates.

\section{Transient behavior of proposed carousel processes}

For the "Average" waste, $15 \mathrm{gpm}$ throughput require a three-column carousel which is $4 \mathrm{ft}$ in diameter and $11.3 \mathrm{ft}$ in segment length, while $25 \mathrm{gpm}$ throughput requires a carousel which is $4.3 \mathrm{ft}$ in diameter and $16 \mathrm{ft}$ in segment length. These two cases are compared in Table 7. Actual carousel simulations are carried out to check the percent column saturation during the transient period and at cyclic steady state. In the carousel process simulations, the port switching occurs when the outlet concentration of the second column reaches $1.3 \times 10^{-3} \mathrm{mg} / \mathrm{L}$. At this time, the first column is taken off-line, the feed is introduced into the second column, and a fresh column introduced at the end of the train (as a guard column). Figure 11 shows the simulated concentration histories at the outlet of each column for two carousel processes, one operated at $15 \mathrm{gpm}$ and the other at $25 \mathrm{gpm}$. Notice that in both cases the outlet concentration of column 2 reaches the specified value of $1.3 \times 10^{-3} \mathrm{mg} / \mathrm{L}$ at the port switching time. The outlet concentration of column 3 (the guard column) is too low to be seen in this figure. Figure 11 also shows that cyclic steady state is established after about three switching periods. The utilization of the lead column is about 99.8 percent before cyclic steady state is established and 99.2 percent at cyclic steady state. This result proves that by choosing the constant pattern $L_{\mathrm{MTZ}}$, one can ensure that percent utilization is high during the startup and after cyclic steady state is established.

\section{Design Alternatives}

There are many alternative carousel designs that can meet SRS waste treatment requirements. The sizes of the carousel columns in Tables 5 and 6 are estimated based on a fixed diameter for Case 1 and a fixed segment length of 16 $\mathrm{ft}$ for Case 2 and the following assumptions: (1) The effective $\mathrm{Cs}^{+}$isotherms of the wastes can be predicted by using the TAMU model with a dilution factor of 1.0 . (2) The $D_{p}$ value is $7.3 \times 10^{-5} \mathrm{~cm}^{2} / \mathrm{min}$ for all wastes. (3) The $L_{\mathrm{MTz}}$ is defined as the length in which $C$ decreases from $0.9 C_{0}$ to $1.3 \times 10^{-3} \mathrm{mg} / \mathrm{L}$. This definition gives a percent utilization of 99.8 during the startup and 99.2 percent at cyclic steady state. One can choose a shorter $L_{\mathrm{MTZ}}$ if a lower percent utilization of the lead column is desired or the level of $\mathrm{Cs}^{+}$in the effluent of column 2 can be higher than $1.3 \times 10^{-3}$ $\mathrm{mg} / \mathrm{L}$. (4) The current design assumes three columns: the lead column is for saturation; the second column is to contain the mass transfer zone; and the third column is a guard column. Each column length is the same as the mass transfer zone length.

Alternatively, the mass transfer zone can be spread among two columns, thus halving the size of the lead column and the guard column in the process. The saturation zone and the guard zone decrease in length, while the mass transfer zone remains fixed, leading to a shorter overall bed length. Table 8 compares the performances of carousel processes with three, four, five, and six column segments. One can see that there is a 50 percent gain in the throughput per bed volume and a 33 percent decrease in the bed length on increasing the number of segments from three to four. However, there is also a 50 percent smaller guard column and one more valve. These factors need to be taken into account in future cost analyses and process optimization studies. 


\section{APPENDIX A (continued)}

\section{Conclusions}

A model-based approach has been developed to design a CST carousel ion exchange process for removing cesium from Savannah River Site wastes. Batch equilibrium data were correlated using a detailed ion exchange model for CST powder (TAMU model). The model predictions were then fit to the Langmuir equation to obtain effective cesium isotherms for six model SRS waste compositions. For CST pellets in SRS standard simulant, a dilution factor from 0.56 to 1.0 is needed to fit the isotherm data. For W29 waste, a dilution factor of 0.56 to 0.66 is needed to fit the column data. However for the "Average" SRS simulant only, a dilution of 1.0 can explain the column data at three linear velocities. It appears that either the inert binder has no effect on the $\mathrm{Cs}^{+}$capacity or the TAMU model underestimates the $\mathrm{Cs}^{+}$loading in this waste simulant. This effective cesium isotherm approach was validated using the data from both small-scale and large-scale column tests at ORNL and small-scale column data for the "Average" SRS waste simulant. Axial dispersion and film mass transfer coefficients were calculated from well-known correlations, and the intraparticle diffusivity was determined by fitting porous model predictions to ORNL and SRS column data. These mass transfer parameters were validated over a wide range of linear velocities for the W29 wastes and the SRS simulant. The intraparticle diffusivities for the two wastes can be well correlated by the Stokes-Einstein equation.

In the design of the carousel process, the length of a single column segment is determined from the length of the mass transfer zone at a given linear velocity. The mass transfer zone is defined as the length of column required to contain the $\mathrm{Cs}^{+}$concentration band from $C=0.9 C_{0}$ to $C=1.3 \times 10^{-3} \mathrm{mg} / \mathrm{L}$ after a constant pattern wave is developed. An analysis of the dimensionless groups in the differential mass balance equations reveals that the normalized mass transfer zone length is proportional to the particle Peclet number. The proportionality constant is a function of the waste composition and the $\mathrm{Cs}^{+}$concentration. For a given waste type, a higher $\mathrm{Cs}^{+}$concentration leads to a shorter mass transfer zone. For a given concentration, a higher Langmuir $a$ value also yields a shorter mass transfer zone. For a given composition, modifications of a given design can be easily made by the use of this simple linear relation.

This study shows that the estimated carousel sizes are most sensitive to the effective cesium isotherms and the intraparticle diffusivities. The bed void fraction also has a direct impact on the size estimates. These key parameters should be confirmed by batch and column tests using actual SRS wastes before implementing the proposed designs for large-scale separation.

\section{Acknowledgment}

The authors wish to thank W. Tamosaitis and C. P. McGinnis for initiating this project; S. Beck and J. Carter for providing background information; R. Jacobs for calculating $\mathrm{Cs}^{+}$isotherms from the TAMU model; R. Anthony for providing the TAMU model as well as many system parameters; D. McCabe for providing SRS simulant batch data; D. D. Lee and P. Taylor for providing W29 column data; and R. D. Hunt, K. K. Anderson, and J. L. Collins for providing the batch test data on the "Average" SRS waste simulant.

\section{Literature Cited}

Anthony, R. G., R. G. Dosch, D. Gu, and C. V. Philip, "Use of Silicotitanates for Removing Cesium and Strontium from Defense Waste," Ind. Eng. Chem. Res., 33, 2702 (1994).

Anthony, R. G., C. V. Philip, and R. G. Dosch, "Selective Adsorption and Ion Exchange of Metal Cations and Anions with Silico-Titanates and Layered Titanates," Waste Manage. (N.Y.), 13, 503 (1993).

Anthony, R. G., Texas A\&M University, personal communication (1998).

Berninger, J. A., R. D. Whitley, and N.-H. L. Wang, "A Versatile Model for Simulation of Reaction and Nonequilibrium Dynamics in Multicomponent Fixed-Bed Adsorption Processes," Comp. Chem. Eng., 15, 749 (1991).

Chung, S. F., and C. Y. Wen, "Longitudinal Dispersion of Liquid Flowing Through Fixed and Fluidized Beds," AIChE J., 14, 857 (1968).

Ernest, Jr., M. V., J. P. Bibler, R. D. Whitley, and N.-H. L. Wang, "Development of a Carousel Ion Exchange Process for Removal of Cesium-137 from Alkaline Nuclear Waste," Ind. Eng. Chem. Res., 36, 275 (1997). 


\section{APPENDIX A (continued)}

Hunt, R. D., K. K. Anderson, and D. D. Lee, "Batch Tests with IONSIV IE-911 and a Simulant of the Savannah River Site's 'Average' Supernatant: Distribution Coefficients vs. Time," Oak Ridge National Laboratory, Oak Ridge, TN (1998).

Koh, J.-H., P. C. Wankat, and N.-H. L. Wang, "Pore and Surface Diffusion and Bulk-Phase Mass Transfer in Packed and Fluidized Beds," Ind. Eng. Chem. Res., 37, 228 (1998).

Lee, D. D., J. F. Walker, Jr., P. A. Taylor, and D. W. Hendrickson, "Cesium-Removal Flow Studies Using Ion Exchange," Environ. Prog., 16, 251 (1997).

Ma, Z., R. D. Whitley, and N.-H. L. Wang, "Pore and Surface Diffusion in Multicomponent Adsorption and Liquid Chromatography Systems," AIChE J., 42, 1244 (1996).

McCabe, D. J., "Crystalline Silicotitanate Examination Results," Technical Report WSRC-RP-94-1123, Westinghouse Savannah River Company, Aiken, SC (1995).

McCabe, D. J., "Examination of Crystalline Silicotitanate Applicability in Removal of Cesium from SRS High Level Waste," Technical Report WSRC-TR-97-0016, Westinghouse Savannah River Company, Aiken, SC (1997).

McGinnis, C. P., R. D. Hunt, S. M. Gibson, and R. L. Gilchrist, "Separation Projects within the U. S. Department of Energy's Underground Storage Tank-Integrated Demonstration," Sep. Sci. Tech., 30, 1741 (1995).

Walker, D. D., W. D. King, D. P. Diprete, L. L. Tovo, D. T. Hobbs, and W. L. Wilmarth, "Cesium Removal from Simulated SRS High-Level Waste Using Crystalline Silicotitanate," Technical Report WSRC-TR-98-00344, Rev. 0, Westinghouse Savannah River Company, Aiken, SC (1998).

Walker, Jr., J. F., P. A. Taylor, R. L. Cummins, B. S. Evans, S. D. Heath, J. D. Hewitt, R. D. Hunt, H. L. Jennings, J. A. Kilby, D. D. Lee, S. Lewis-Lambert, S. A. Richardson, and R. F. Utrera, "Cesium Removal Demonstration Using Crystalline Silicotitanate Sorbent for Processing Melton Valley Storage Tank Supernate: Final Report," Technical Report ORNL/TM-13503, Oak Ridge National Laboratory, Oak Ridge, TN (1998).

Whitley, R. D., Dynamics of Nonlinear Multicomponent Chromatography-Interplay of Mass Transfer, Intrinsic Sorption Kinetics, and Reaction, Ph.D. Thesis, Purdue University, West Lafayette, IN (1990).

Wilson, E. J., and C. J. Geankoplis, “Liquid Mass Transfer at Very Low Reynolds Numbers in Packed Beds," Ind. Eng. Chem. Fundam., 5, 9 (1966).

Zheng, Z., R. G. Anthony, and J. E. Miller, "Modeling Multicomponent Ion Exchange Equilibrium Utilizing Hydrous Crystalline Silicotitanates by a Multiple Interactive Ion Exchange Site Model," Ind. Eng. Chem. Res., 36, 2427 (1997). 


\section{APPENDIX A (continued)}

\section{Notation}

$a=$ Langmuir coefficient, $\mathrm{mg} / \mathrm{mL}$ B.V.

$b=$ Langmuir coefficient, $\mathrm{mL} / \mathrm{mg}$

$C=$ bulk-phase solute concentration, $\mathrm{mg} / \mathrm{mL}$

$C_{p}=$ pore-phase solute concentration, $\mathrm{mg} / \mathrm{mL}$

$C_{0}=$ column inlet solute concentration, $\mathrm{mg} / \mathrm{mL}$

$D=$ diffusivity, $\mathrm{cm}^{2} / \mathrm{min}$

$D_{p}=$ intraparticle diffusivity, $\mathrm{cm}^{2} / \mathrm{min}$

$D^{\infty}=$ Brownian diffusivity, $\mathrm{cm}^{2} / \mathrm{min}$

$E_{b}=$ axial dispersion coefficient, $\mathrm{cm}^{2} / \mathrm{min}$

$F=$ volumetric flow rate, $\mathrm{gpm}$ or $\mathrm{mL} / \mathrm{min}$

I. D. = column inner diameter, $\mathrm{ft}$

$k_{B}=$ Boltzmann's constant, $4.97 \times 10^{-13} \mathrm{~g} \cdot \mathrm{cm}^{2} / \mathrm{K} \cdot \mathrm{min}^{2}$

$k_{f}=$ film mass transfer coefficient, $\mathrm{cm} / \mathrm{min}$

$L_{c}=$ column length, $\mathrm{cm}$ or $\mathrm{ft}$

$q=$ solid-phase solute concentration, $\mathrm{mg} / \mathrm{mL} \mathrm{S.V}$.

$r=$ radial distance from center of adsorbent particle, $\mathrm{cm}$

$R_{0}=$ solute radius, $\mathrm{cm}$

$R_{p}=$ adsorbent particle radius, $\mathrm{cm}$ or $\mu \mathrm{m}$

$t=$ time, $\min$

$T=$ absolute temperature, $\mathrm{K}$

TPBV $=$ throughput per bed volume, $\mathrm{gpm} / \mathrm{ft}^{3}$

$u_{0}=$ linear interstitial velocity, $\mathrm{cm} / \mathrm{min}$

$u_{s}=$ linear superficial velocity, $\mathrm{cm} / \mathrm{min}$

$V_{c}=$ column volume, $\mathrm{mL}$ or $\mathrm{L}$

$z=$ axial distance, $\mathrm{cm}$

\section{Greek letters}

$\varepsilon_{b}=$ bed void fraction, dimensionless

$\varepsilon_{p}=$ intraparticle void fraction, dimensionless

$\mu=$ solution viscosity, $\mathrm{g} / \mathrm{cm} \cdot \mathrm{min}$

\section{Dimensionless variables}

$k_{f}=k \delta u_{0}$ (film mass transfer number)

$L_{c}{ }^{*}=L_{c} d R_{p}$ (dimensionless column length)

$L_{\mathrm{MTZ}}{ }^{*}=L_{\mathrm{MTZ}} / R_{p}$ (dimensionless mass transfer zone length)

$\mathrm{Pe}_{b}=u_{0} L_{c} / E_{b}$ (bulk Peclet number)

$\mathrm{Pe}_{p}=u_{0} R_{p} / \varepsilon_{p} D_{p}$ (particle Peclet number)

$x=z / L_{c}$ (dimensionless axial position)

$\theta=t u_{0} / L_{c}$ (dimensionless time)

$\xi=r / R_{p}$ (dimensionless radial position)

$\phi_{b}=\left(1-\varepsilon_{b}\right) / \varepsilon_{b}$ (particle/bulk phase ratio)

$\phi_{p}=\left(1-\varepsilon_{p}\right) / \varepsilon_{p}$ (solid/pore phase ratio) 


\section{APPENDIX A (continued)}

TABLE I. Dimensionless parameters in the pore diffusion model (Eqs. 3 and 4).

\begin{tabular}{cll} 
Parameter & & Definition \\
\cline { 1 - 1 }$X$ & & $z L_{c}$ \\
$\theta$ & & $t u_{d} / L_{c}$ \\
$\mathrm{xi}$ & $\mathrm{r} / \mathrm{R} \_\mathrm{p}$ \\
$\varphi_{b}$ & & $\left(1-\varepsilon_{b}\right) / \varepsilon_{b}$ \\
$\varphi_{p}$ & $\left(1-\varepsilon_{p}\right) / \varepsilon_{p}$ \\
$L_{c}$ & $L_{d} / R_{p}$ \\
$k_{f}^{*}$ & $k_{f} / u_{0}$ \\
$\mathrm{Pe} e_{b}$ & $u_{0} L_{d} / E_{b}$ \\
$\mathrm{Pe}_{p}$ & $u_{0} R_{p} / D_{p}$
\end{tabular}

\begin{tabular}{ll} 
Description & Value $^{\dagger}$ \\
\cline { 2 - 2 } dimensionless axial distance & $0-1$ \\
dimensionless time & $0-1$ \\
dimensionless radial distance & $0-1$ \\
particle/bulk phase ratio & 1.0 \\
solid/pore phase ratio & 3.2 \\
dimensionless column length & $1.8 \times 10^{4}$ \\
film mass transfer/convection & $3.3 \times 10^{-2}$ \\
convection/axial dispersion & $3.8 \times 10^{3}$ \\
convection/intraparticle diffusion & $2.5 \times 10^{3}$
\end{tabular}

${ }^{{ }^{\mathrm{I}} \mathrm{ID} .}=4 \mathrm{ft} . \quad L_{c}=11.3 \mathrm{ft} . \quad u_{s}=4.9 \mathrm{~cm} / \mathrm{min} . \quad R_{p}=187.5 \mu \mathrm{m} . \quad D_{p}=7.3 \times 10^{-5} \mathrm{~cm}^{2} / \mathrm{min}$.

TABLE 2. SRS waste compositions.

\begin{tabular}{|c|c|c|c|c|c|c|}
\hline \multirow[b]{2}{*}{ Component } & \multicolumn{6}{|c|}{ Concentration $[\mathrm{mol} / \mathrm{L}]$} \\
\hline & Avg & Avg-b & $\underline{\mathrm{OH}}$ & $\underline{\mathrm{OH}}-\mathrm{b}$ & $\underline{\mathrm{NO}_{3}}$ & $\underline{\mathrm{NO}_{3}-\mathrm{b}}$ \\
\hline $\mathrm{Na}^{+}$ & 5.6 & 5.47 & 5.6 & 5.48 & 5.6 & 5.45 \\
\hline $\mathrm{K}^{+}$ & 0.015 & 0.15 & 0.03 & 0.15 & 0.0041 & 0.15 \\
\hline $\mathrm{Cs}^{+}$ & 0.00014 & 0.0007 & 0.00037 & 0.0007 & 0.00014 & 0.0007 \\
\hline $\mathrm{AlO}_{2}^{-}$ & 0.31 & 0.31 & 0.27 & 0.27 & 0.32 & 0.32 \\
\hline $\mathrm{C}_{2} \mathrm{O}_{4}^{2}-$ & 0.008 & 0.008 & 0.008 & 0.008 & 0.008 & 0.008 \\
\hline $\mathrm{CO}_{3}{ }^{2-}$ & 0.16 & 0.16 & 0.17 & 0.17 & 0.16 & 0.16 \\
\hline $\mathrm{MoO}_{4}{ }^{2-}$ & 0.0002 & 0.0002 & 0.0002 & 0.0002 & 0.0002 & 0.0002 \\
\hline $\mathrm{SiO}_{3}^{2-}$ & 0.004 & 0.004 & 0.004 & 0.004 & 0.004 & 0.004 \\
\hline $\mathrm{SO}_{4}^{2-}$ & 0.15 & 0.15 & 0.030 & 0.030 & 0.22 & 0.22 \\
\hline $\mathrm{PO}_{4}^{3-}$ & 0.010 & 0.010 & 0.008 & 0.008 & 0.010 & 0.010 \\
\hline $\mathrm{Cl}^{-}$ & 0.025 & 0.025 & 0.010 & 0.010 & 0.040 & 0.040 \\
\hline$F$ & 0.032 & 0.032 & 0.010 & 0.010 & 0.050 & 0.050 \\
\hline $\mathrm{NO}_{2}^{-}$ & 0.52 & 0.52 & 0.74 & 0.74 & 0.37 & 0.37 \\
\hline $\mathrm{NO}_{3}^{-}$ & 2.14 & 2.14 & 1.10 & 1.10 & 2.84 & 2.84 \\
\hline $\mathrm{OH}^{-}$ & 1.91 & 1.91 & 3.05 & 3.05 & 1.17 & 1.17 \\
\hline
\end{tabular}

TABLE 3. Langmuir coefficients for modeling SRS and ORNL column tests.

Waste

SRS average

SRS average, bounding

SRS high $\mathrm{OH}$

SRS high $\mathrm{OH}$, bounding

SRS high $\mathrm{NO}_{3}$

SRS high $\mathrm{NO}_{3}$, bounding

MVST-W29
$a[\mathrm{~mL} / \mathrm{mL}$ B.V.]

2400

1530

2900

1960

2030

1280

846
$b[\mathrm{~mL} / \mathrm{mg}]$

30.9

19.8

37.6

25.3

26.3

16.7

11.9 


\section{APPENDIX A (continued)}

TABLE 4. System and mass transfer parameters used in carousel simulations.

\begin{tabular}{|c|c|c|c|}
\hline Parameter & Value, $15 \mathrm{gpm}$ & Value, $25 \mathrm{gpm}$ & Source \\
\hline I. D. $[\mathrm{ft}]$ & 4.0 & 4.3 & \\
\hline$L_{c}[\mathrm{ft}]$ & 11.3 & 16.0 & \\
\hline$R_{\mathrm{p}}[\mu \mathrm{m}]$ & 187.5 & 187.5 & McCabe (1995) \\
\hline$\varepsilon_{b}[-]$ & 0.50 & 0.50 & Anthony (1998) \\
\hline$\varepsilon_{p}[-]$ & 0.24 & 0.24 & Anthony (1998) \\
\hline$D_{\text {infty }}\left[\mathrm{cm}^{2} / \mathrm{min}\right]$ & $9.4 \times 10^{-4}$ & $9.4 \times 10^{-4}$ & Ernest et al. (1997) \\
\hline$D_{p}\left[\mathrm{~cm}^{2} / \mathrm{min}\right]$ & $7.3 \times 10^{-5}$ & $7.3 \times 10^{-5}$ & Stokes-Einstein \\
\hline$k_{f}[\mathrm{~cm} / \mathrm{min}]$ & 0.316 & 0.357 & Wilson-Geankoplis(1966) \\
\hline$E_{b}\left[\mathrm{~cm}^{2} / \mathrm{min}\right]$ & 0.883 & 1.27 & Chung-Wen (1968) \\
\hline
\end{tabular}

TABLE 5. Case 1. Column length requirement for a fixed column diameter of $4 \mathrm{ft}$. SRS wastes are as defined in Table 2 . The letter $b$ indicates a high $K^{+}$(bounding) case. $R_{p}=187.5 \mu \mathrm{m}$.

$D_{p}=7.3 \times 10^{-5} \mathrm{~cm}^{2} / \mathrm{min} . L_{\mathrm{MTZ}}=$ single column length in a three column carousel. $L_{\text {tot }}=3 \times L_{\mathrm{MTZ}}$.

TAMU equilibrium parameters are used without a dilution factor.

\begin{tabular}{|c|c|c|c|c|c|}
\hline SRS waste & Flow rate [gpm] & $\underline{u_{s}}[\mathrm{~cm} / \mathrm{min}]$ & $\underline{u}_{0}[\mathrm{~cm} / \mathrm{min}]$ & $\underline{P e}_{p}$ & $\underline{L}_{\mathrm{MTZ}}[\mathrm{ft}]$ \\
\hline \multirow[t]{2}{*}{ Average } & 15 & 4.9 & 9.8 & $2.50 \times 10^{3}$ & 11.3 \\
\hline & 25 & 8.1 & 16.2 & $4.16 \times 10^{3}$ & 18.6 \\
\hline \multirow[t]{2}{*}{ Average (b) } & 15 & 4.9 & 9.8 & $2.50 \times 10^{3}$ & 5.3 \\
\hline & 25 & 8.1 & $\cdot 16.2$ & $4.16 \times 10^{3}$ & 8.7 \\
\hline \multirow[t]{2}{*}{$\mathrm{High} \mathrm{OH}$} & 15 & 4.9 & 9.8 & $2.50 \times 10^{3}$ & 5.1 \\
\hline & 25 & 8.1 & 16.2 & $4.16 \times 10^{3}$ & 8.4 \\
\hline \multirow[t]{2}{*}{ High OH (b) } & 15 & 4.9 & 9.8 & $2.50 \times 10^{3}$ & 4.5 \\
\hline & 25 & 8.1 & 16.2 & $4.16 \times 10^{3}$ & 7.4 \\
\hline \multirow[t]{2}{*}{$\mathrm{High} \mathrm{NO}_{3}$} & 15 & 4.9 & 9.8 & $2.50 \times 10^{3}$ & 12.8 \\
\hline & 25 & 8.1 & 16.2 & $4.16 \times 10^{3}$ & 20.9 \\
\hline \multirow[t]{2}{*}{$\mathrm{High} \mathrm{NO}_{3}$ (b) } & 15 & 4.9 & 9.8 & $2.50 \times 10^{3}$ & 6.0 \\
\hline & 25 & 8.1 & 16.2 & $4.16 \times 10^{3}$ & 9.9 \\
\hline
\end{tabular}




\section{APPENDIX A (continued)}

TABLE 6. Case 2. Column diameter requirement for a fixed column-segment length of $16 \mathrm{ft}$. $R_{p}=187.5 \mu \mathrm{m} . D_{p}=7.3 \times 10^{-5} \mathrm{~cm}^{2} / \mathrm{min}$.

\begin{tabular}{|c|c|c|c|c|}
\hline$\underline{\text { SRS waste }}$ & Flow rate [gpm] & $\underline{u_{s}}[\mathrm{~cm} / \mathrm{min}]$ & $\underline{u}_{0}[\mathrm{~cm} / \mathrm{min}]$ & I.D. $[\mathrm{ft}]$ \\
\hline \multirow[t]{2}{*}{ Average } & 15 & 7.0 & 16.0 & 3.3 \\
\hline & 25 & 7.0 & 16.0 & 4.3 \\
\hline \multirow[t]{2}{*}{ Average (b) } & 15 & 14.9 & 29.8 & 2.3 \\
\hline & 25 & 14.9 & 29.8 & 3.0 \\
\hline \multirow[t]{2}{*}{ High OH } & 15 & 15.4 & 30.8 & 2.2 \\
\hline & 25 & 15.4 & 30.8 & 2.9 \\
\hline \multirow[t]{2}{*}{ High OH (b) } & 15 & 17.5 & 35.0 & 2.1 \\
\hline & 25 & 17.5 & 35.0 & 2.7 \\
\hline \multirow[t]{2}{*}{ High $\mathrm{NO}_{3}$} & 15 & 6.2 & 12.4 & 3.5 \\
\hline & 25 & 6.2 & 12.4 & 4.6 \\
\hline \multirow[t]{2}{*}{ High $\mathrm{NO}_{3}(\mathrm{~b})$} & 15 & 13.1 & 26.2 & 2.4 \\
\hline & 25 & 13.1 & 26.2 & 3.1 \\
\hline
\end{tabular}

TABLE 7. Comparison of two carousel processes operated at two different volumetric flow rates. Isotherm is based on SRS average nominal waste with a dilution factor of $1.0 . D_{p}=7.3 \times 10^{-5} \mathrm{~cm}^{2} / \mathrm{min}$. $R_{p}=187.5 \mu \mathrm{m}$.

$\begin{array}{lll}\text { Flow rate [gpm] } & 15 & 25 \\ \text { I. D. [ft] } & 4.0 & 4.3 \\ \text { Interstitial velocity [cm/min] } & 9.7 & 16.0 \\ \text { Superficial velocity [cm/min] } & 4.9 & 8.0 \\ L_{\text {MTz }}[\mathrm{ft}] & 11.3 & 16.0 \\ \text { Total bed volume [ft }{ }^{3} \text { ] } & 426 & 697 \\ \text { Percent column saturation } & 99 & 99 \\ \text { Switch time [days] } & 74 & 73\end{array}$

TABLE 8. Comparison of carousel configurations with varying numbers of segments. Column cross-sectional area and flow rate are fixed.

Number of segments

$\begin{array}{ll}3 & 3 L_{\mathrm{MTZ}} \\ 4 & 2 L_{\mathrm{MTZ}} \\ 5 & 1.67 L_{\mathrm{MTZ}} \\ 6 & 1.5 L_{\mathrm{MTZ}}\end{array}$

Guard column length

$$
\begin{aligned}
& L_{\mathrm{MTZ}} \\
& 0.50 L_{\mathrm{MTZ}} \\
& 0.33 L_{\mathrm{MTZ}} \\
& 0.25 L_{\mathrm{MTZ}}
\end{aligned}
$$

Number of valves

$$
\begin{aligned}
& 3 \\
& 4 \\
& 5 \\
& 6
\end{aligned}
$$




\section{APPENDIX A (continued)}

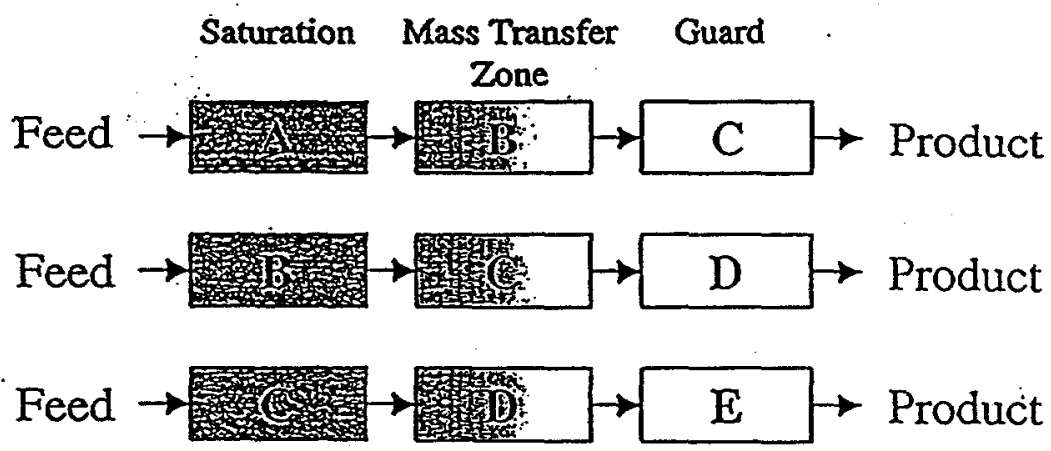

Figure 1. Proposed carousel process. Column 1 is the saturation zone. Column 2 contains the mass transfer zone. Column 3 is a guard zone.

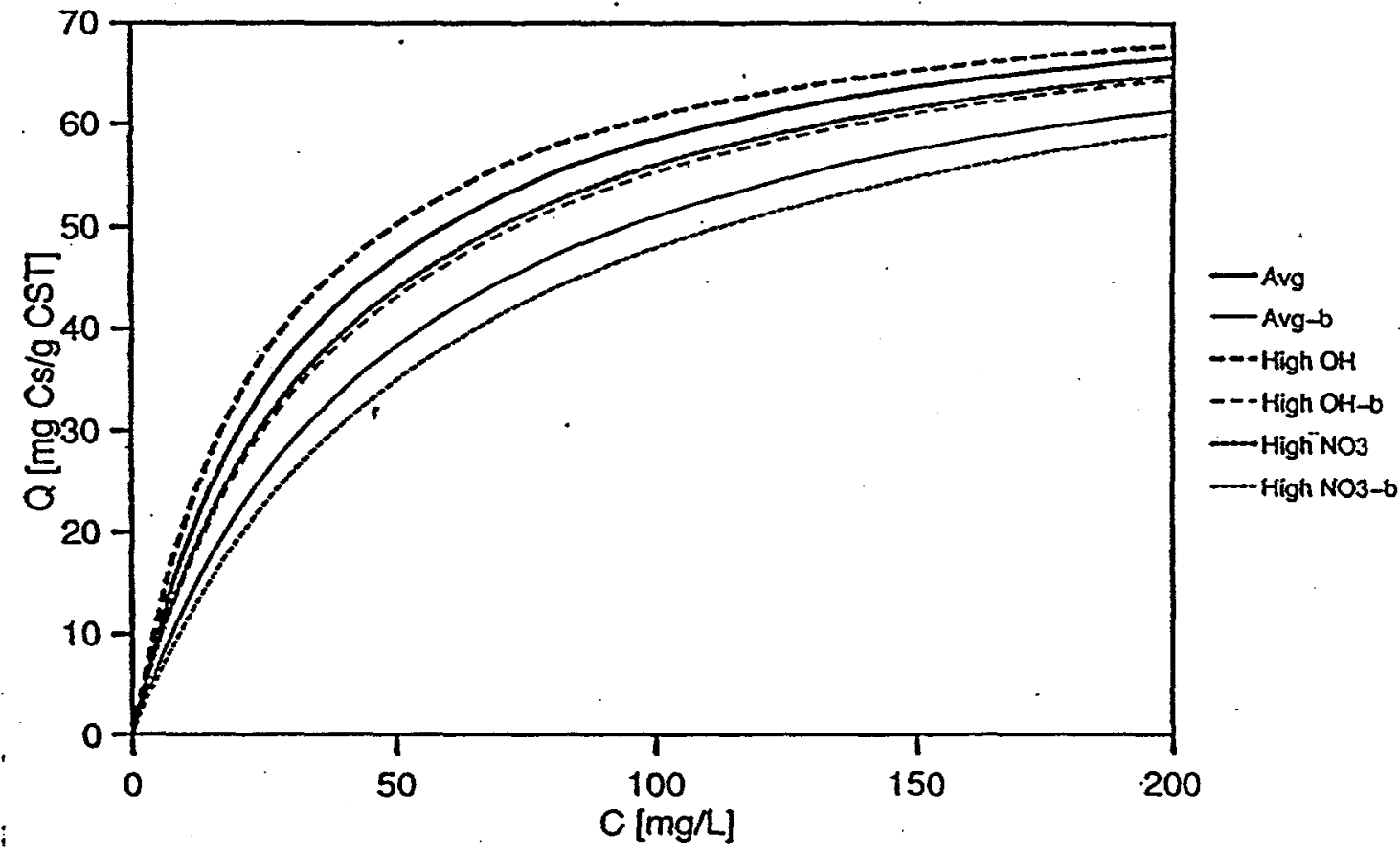

Figure 2. $\mathrm{Cs}^{+} / \mathrm{CST}$ isotherms showing model predictions of bounding cases: average SRS, high hydroxide, and high nitrate. Experimental data are shown in symbols. 


\section{APPENDIX A (continued)}
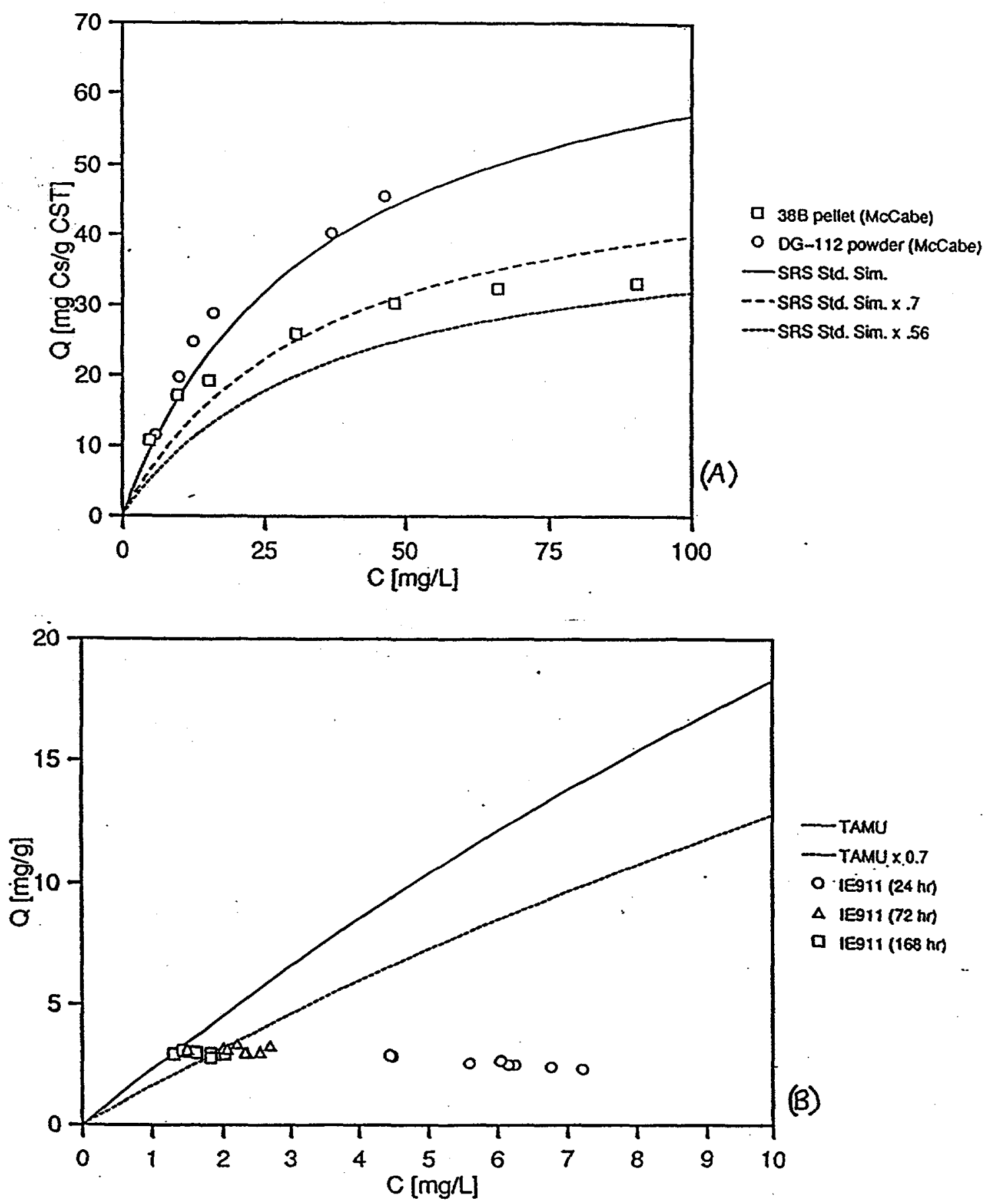

Figure 3. (a) $\mathrm{Cs}^{+} / \mathrm{CST}$ isotherms in SRS high level waste. Solid line: TAMU prediction for powdered CST Circles: experimental batch $\mathrm{Cs}^{+}$uptake on powdered CST. Triangles: batch data on 38B. Dashed lines: TAMU model prediction multiplied by 0.56 and 0.7 . (b) $\mathrm{Cs}^{+} / \mathrm{CST}$ isotherms in SRS average waste. Symbols denote batch samples at 24,72 , and 168 hours. 


\section{APPENDIX A (continued)}

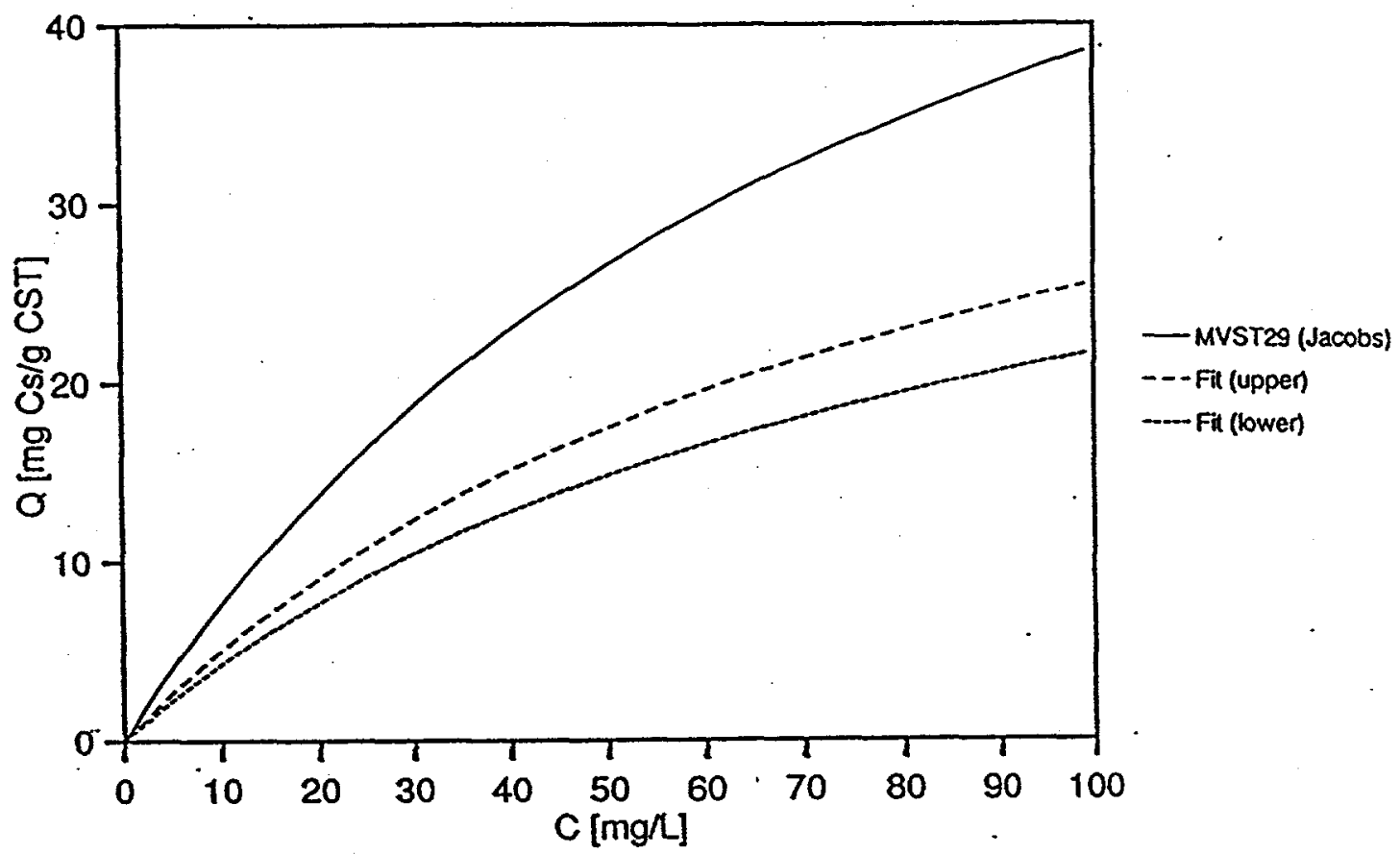

Figure 4. $\mathrm{Cs}^{+} / \mathrm{CST}$ isotherm. The solid line denotes the TAMU model of $\mathrm{Cs}^{+}$uptake on powdered CST in MVST-29 waste. The dashed lines represent the upper and lower bounds of isotherms that predict column data on engineered CST in MVST-29 waste. 


\section{APPENDIX A (continued)}
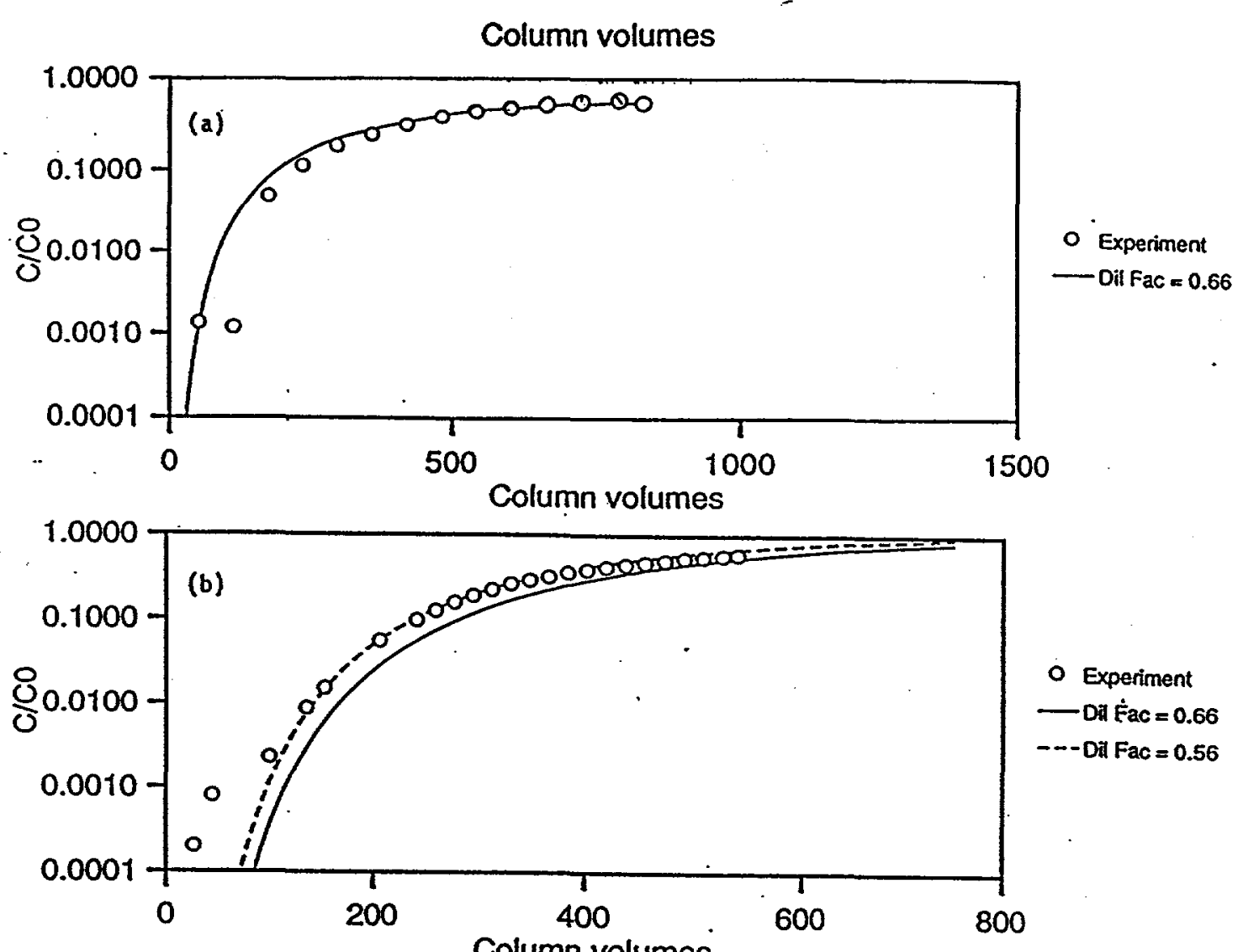

$$
\begin{aligned}
& \text { Oxperiment } \\
& \text {-Da Fac }=0.66 \\
& --D \text { Da Fac }=0.56
\end{aligned}
$$

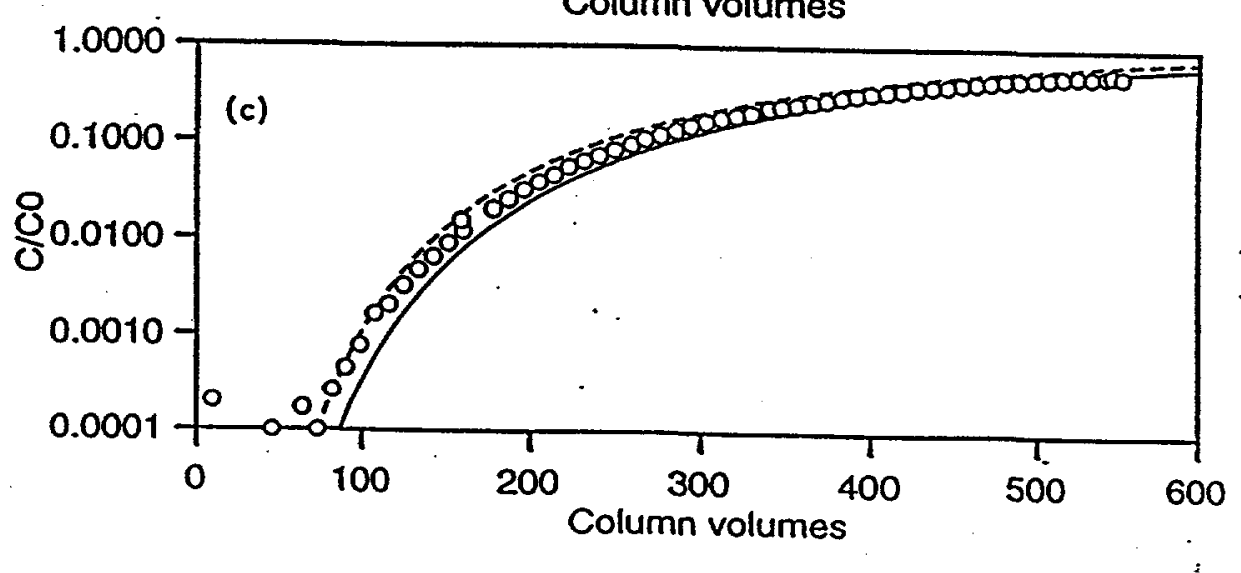

- Experinent

Dil Fac $=0.66$

-- Oil Fac $=0.56$

Figure 5. CsRD support column experiments compared to simulation. $D_{p}=1.0 \times 10^{-4} \mathrm{~cm}^{2} / \mathrm{min}$. (a) $V_{c}=10.0 \mathrm{~mL} ; \mathrm{I}$. D. $=1.45 \mathrm{~cm} ; F=1.00 \mathrm{~mL} / \mathrm{min}$. (b) $V_{c}=12.54 \mathrm{~mL} ;$ I. D. $=1.45 \mathrm{~cm} ; F=0.627 \mathrm{~mL} / \mathrm{min}$. (c) $V_{c}=23.2 \mathrm{~mL}$ total; 1. D. $=$ $1.45 \mathrm{~cm} ; F=1.16 \mathrm{~mL} / \mathrm{min}$. 


\section{APPENDIX A (continued)}

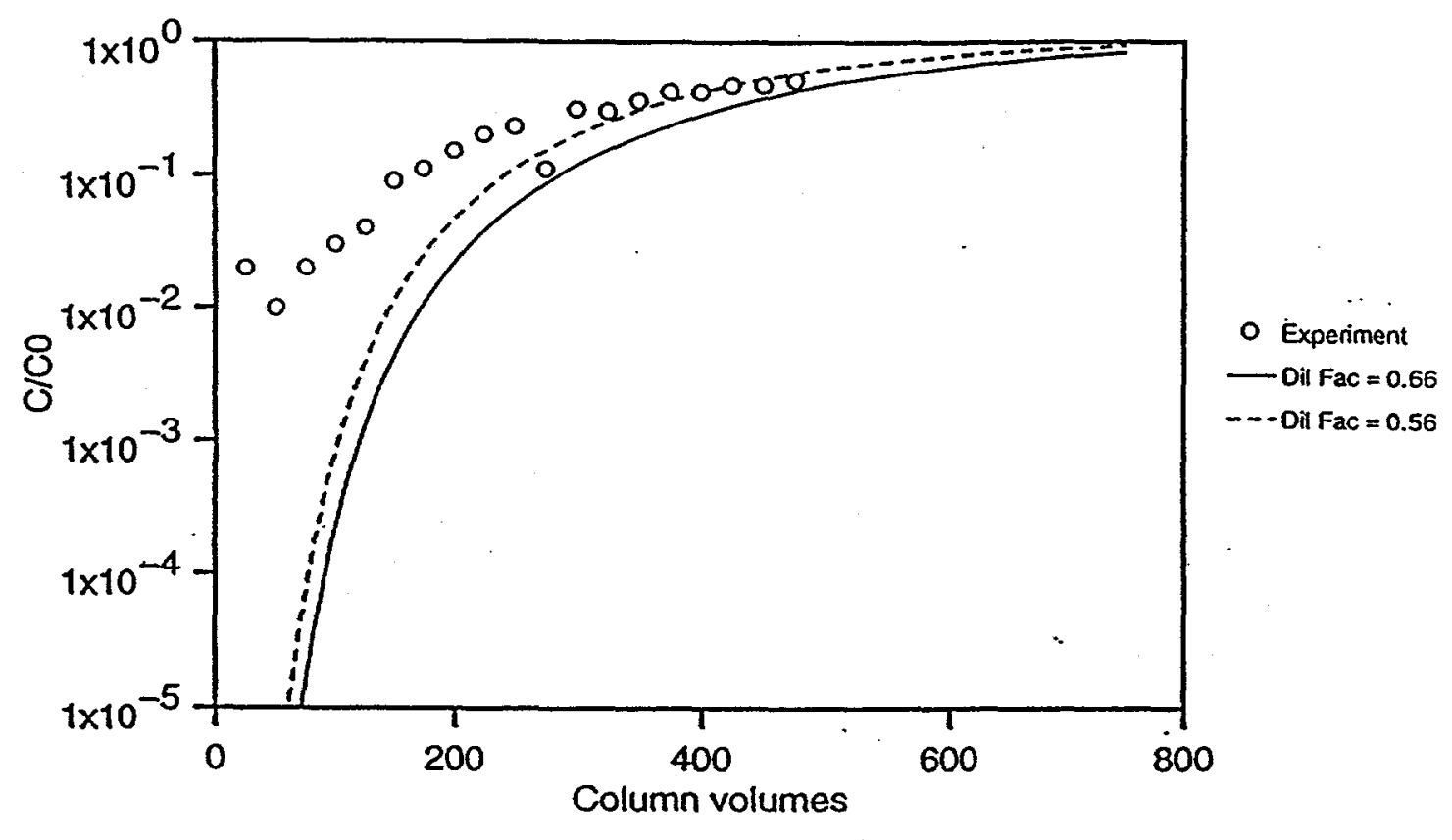

Figure 6. CsRD column experiment compared to simulation. Isotherms are estimated by multiplying TAMU model prediction by 0.56 and 0.66 . Column volume: $38 \mathrm{~L}$. Column diameter. $30 \mathrm{~cm}$. Flow rate: $1.9 \mathrm{~L} / \mathrm{min} . D_{p}=1.0 \times 10^{-4}$ $\mathrm{cm}^{2} / \mathrm{min}$. 
APPENDIX A (continued)
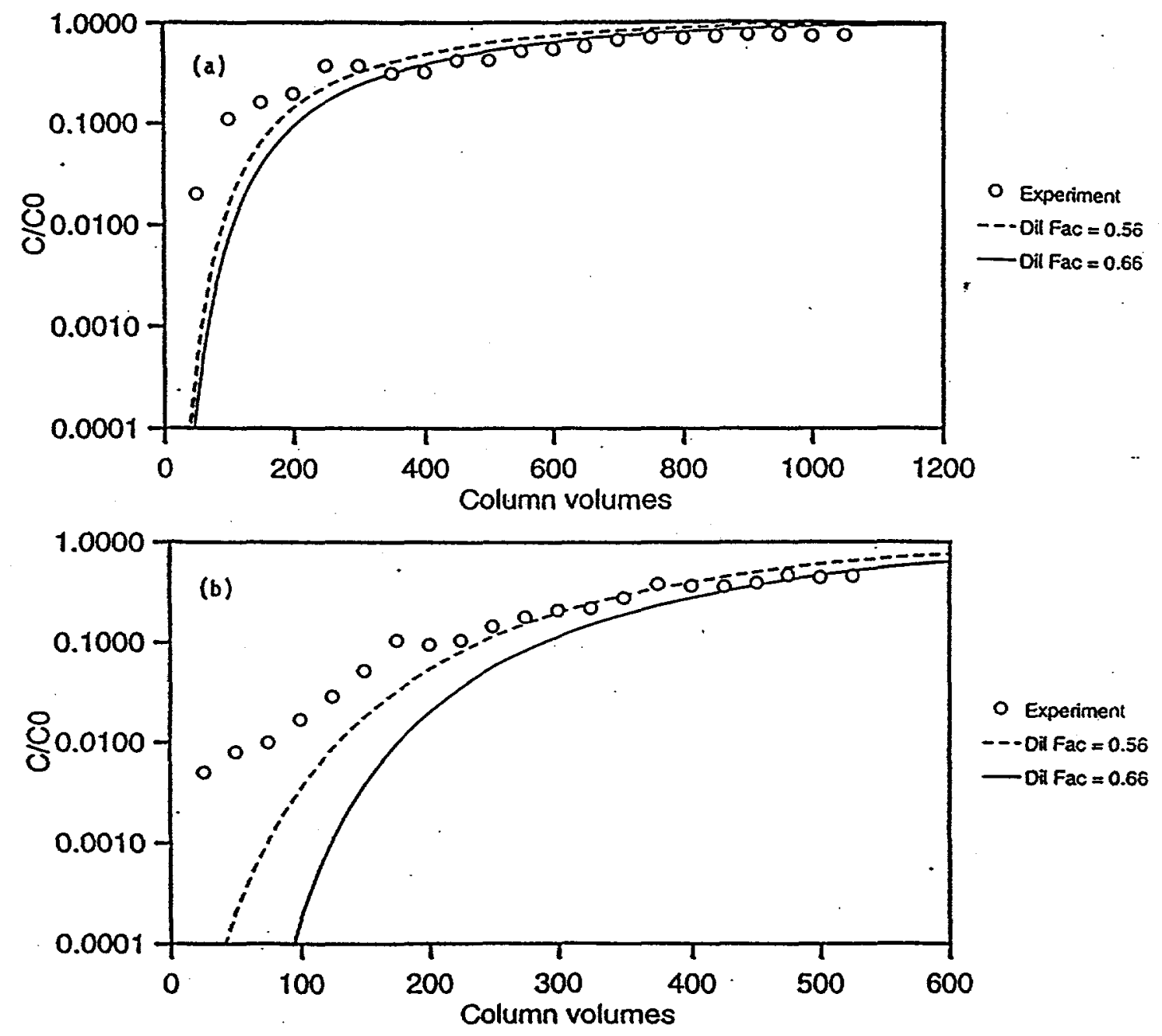

Figure 7. CsRD two-column experiment compared to simulation. Isotherm is estimated by multiplying TAMU model prediction by 0.56 and 0.66 . (a) Lead column effluent history. (b) Second column effluent history. Column volume: 38 $\mathrm{L}$ (each column). Column diameter: $30 \mathrm{~cm}$. Flow rate: $3.8 \mathrm{~L} / \mathrm{min} . D_{p}=1.0 \times 10^{-4} \mathrm{~cm}^{2} / \mathrm{min}$. 


\section{APPENDIX A (continued)}
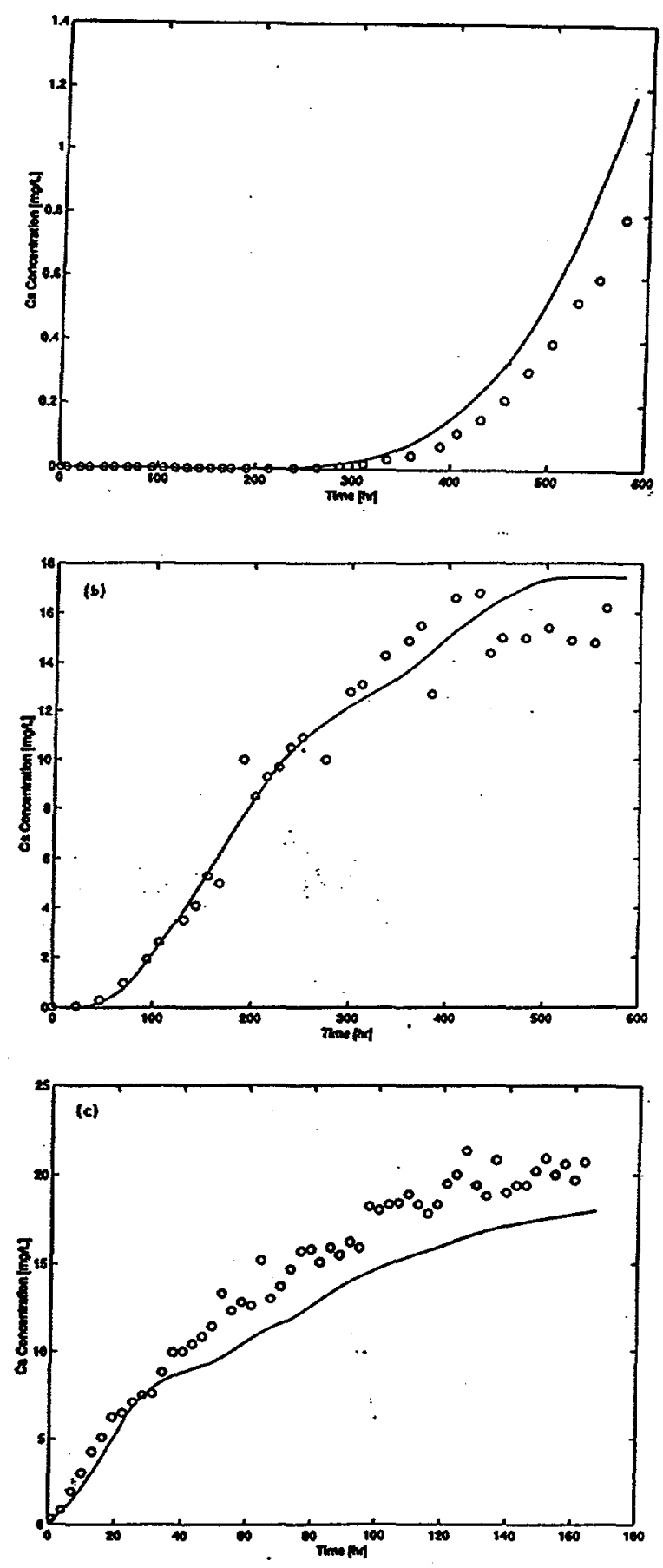

Figure 8. WSRC column experiments compared to simulation. The isotherm parameters are from the TAMU model, without a dilution factor. Column volume: $17.7 \mathrm{~mL}$. (a) $u_{s}=0.27 \mathrm{~cm} / \mathrm{min}$. (b) $u_{s}=0.98 \mathrm{~cm} / \mathrm{min}$. (c) $u_{s}=4.1 \mathrm{~cm} / \mathrm{min}$. 


\section{APPENDIX A (continued)}
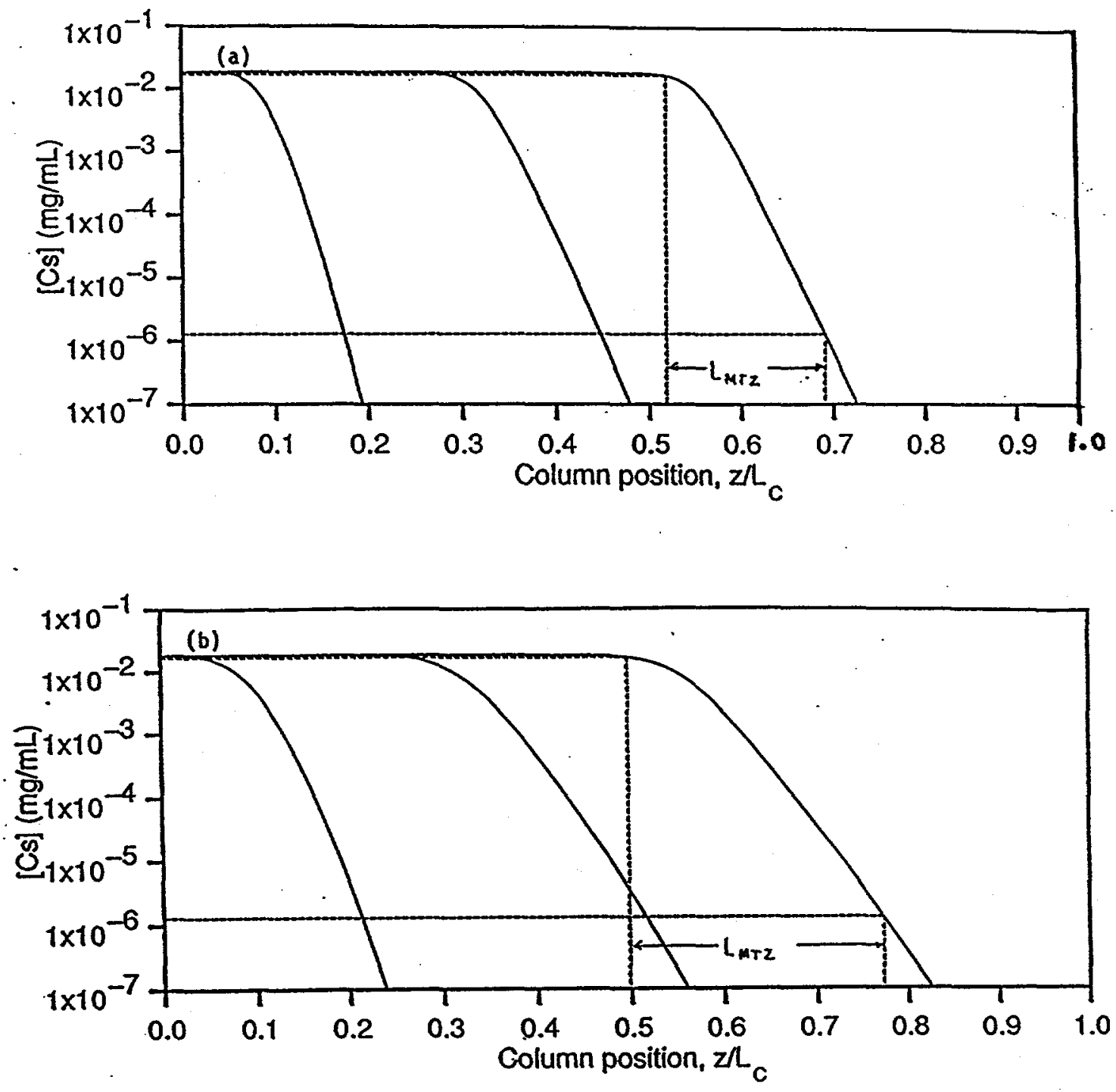

Figure 9. Mass transfer zone length determination for cesium in average SRS waste (nominal). Column diameter: $4 \mathrm{ft}$. Column length: $66 \mathrm{ft}$. Dilution factor: 0.7. $L_{\mathrm{MTZ}}$ determined from the profile where the concentration decreases from $C / C_{0}=0.9$ to $C=1.3 \times 10^{-3} \mathrm{mg} / \mathrm{L}$. (a) $F=15 \mathrm{gpm}$. $u_{s}=4.9 \mathrm{~cm} / \mathrm{min}$. (b) $F=25 \mathrm{gpm}$. $u_{s}=8.1 \mathrm{~cm} / \mathrm{min}$. 


\section{APPENDIX A (continued)}

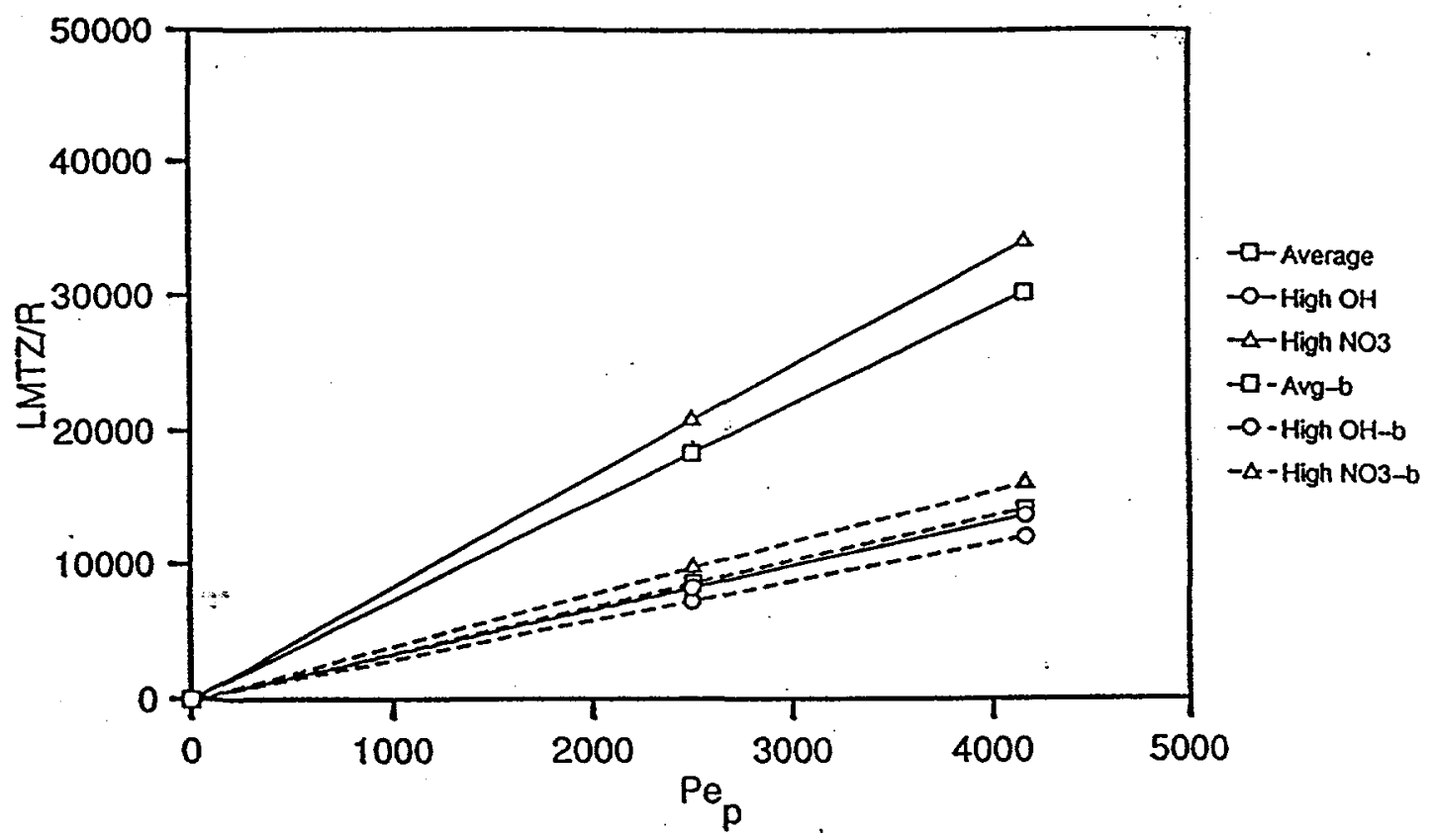

Figure 10. Dimensionless mass transfer zone length as a function of the Peclet number. 


\section{APPENDIX A (continued)}
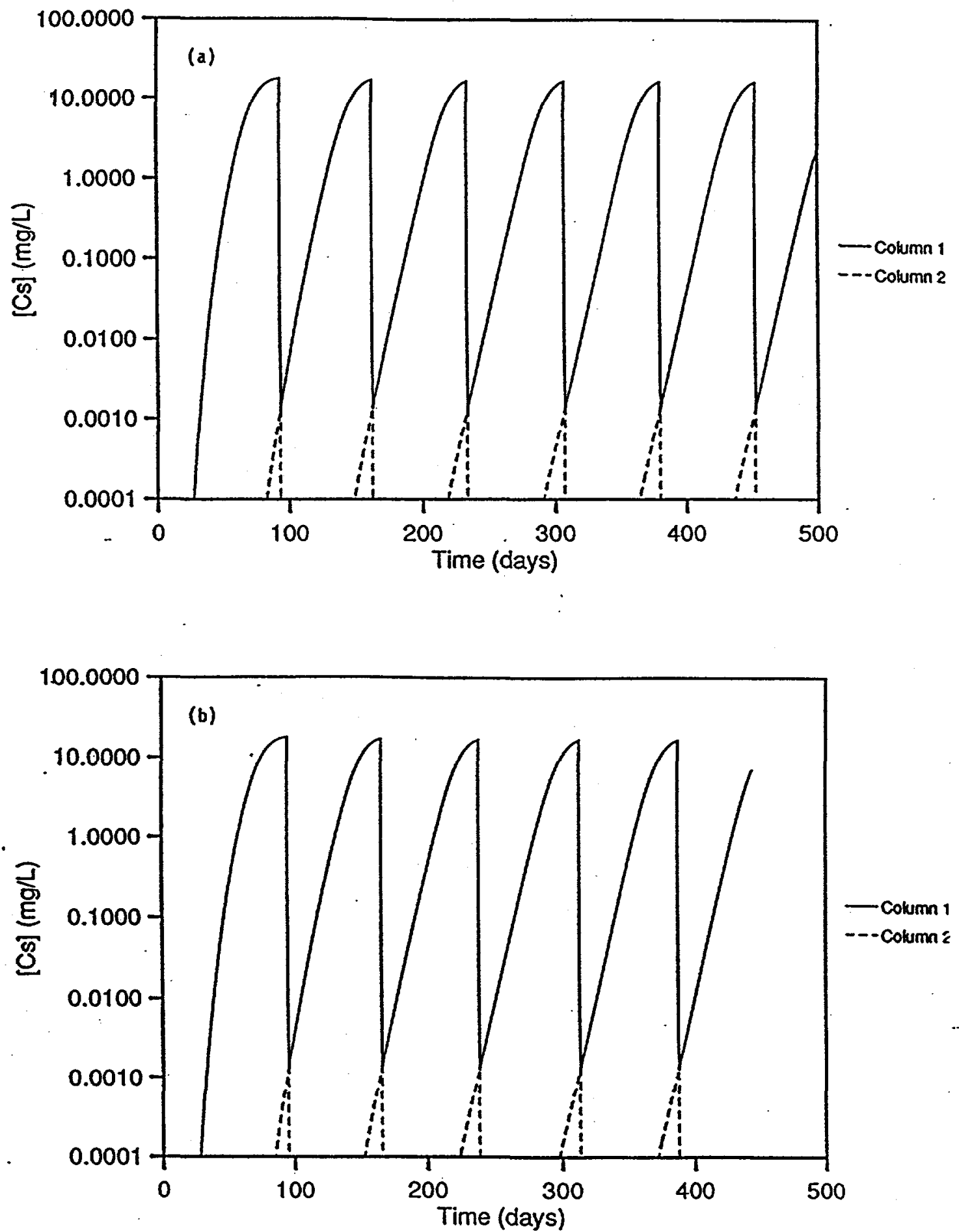

Figure 11. Simulated $\mathrm{Cs}^{+}$concentration histories at each outlet port in a three-column carousel process. Feed: average SRS. $D_{p}=7.3 \times 10^{-5} \mathrm{~cm}^{2} / \mathrm{min}$. Saturation of lead column: 99 percent. Solid line: lead column history. Dashed line: second column history. The outlet concentration of the third column is below $10 \$^{\wedge}\{-7\} \$ \mathrm{mg} / \mathrm{mL}$. (a) Total bed length: $33.9 \mathrm{ft}$. Flow rate: $15 \mathrm{gpm}$. (b) Total bed length: $48.0 \mathrm{ft}$. Flow rate: $25 \mathrm{gpm}$. 


\author{
APPENDIX B
}

\title{
Treating Savannah River Waste Using UOP IONSIV IE-911: \\ Revised Design Based on Laboratory Column Experiments.
}

\author{
By \\ M. E. Huckman, I. M. Latheef, \& R. G. Anthony \\ Kinetics, Catalysis, \& Reaction Engineering Laboratory \\ Department of Chemical Engineering, Texas A\&M University, College Station, Texas. \\ October 18, 1998
}

\section{Introduction}

This report provides an updared design of an ion exchange carousel system to process SRS high level waste. The original design cases prepared by Texas A\&M University (TAMU) were presented in a report entitled, "Treating Savannah River Waste Using UOP IONSIV IE-911," submitted on September 25, 1998. These original designs were conducted using an ion exchange carousel column model, which uses a two-phase homogeneous particle balance, Langmuir isotherm, and accounts for axial dispersion. The effective diffusivity was estimated from batch kinetic experiments conducted at TAMU on similar waste solutions. The axial dispersion and film mass transfer coefficients were estimated from correlations. The equilibrium values were obtained from $R$. Jacobs, who used the TAMU equilibrium powder model to generate data for the SRS waste simulants. The equilibrium values were adjusted by a $70 \%$ dilution factor to account for the presence of a binder in the final engineered form.

The updatod design presented here was based on recent bench-scale column experiments conducted using simulated SRS Average waste at 3 flow rates $(1.6 \mathrm{CV} / \mathrm{h}, 5.8 \mathrm{CV} / \mathrm{h}$, and 22.1 CV/h) and batch equilibrium data for the Average waste. The details of these experiments and procedures used are described in the report entitled, "Cesium Removal from Simulated SRS High-Level Waste Using Crystalline Silicotitanate" (WSRC-TR-98-00344, Rev. 0). The additional experimental data were used to verify or adjust the estimates used in the original report of September 25, 1998. 


\section{APPENDIX B (continued)}

\section{Equillbrium}

In the original report, the equilibrium behavior of the IE-911 granules in the SRS waste was estimated using the previously developed Texas A\&M equilibrium model for the IE-910 powder. To account for the dilution of the powder in the final engineered form, a $70 \%$ dilution factor was used to adjust the model-predicted values. The recent experimental measurements (WSRC-TR98-00344, Rev. 0) and equilibrium data presented in WSRC-RP-97-0016 have indicated that the 70\% dilution factor significantly underestimates the actual IE-911 Cs loading. Figure 1 shows the recently measured data along with model-predicted results and the model results adjusted by $70 \%$. This graph indicates that no dilution factor is required for the model-predicted values.

Furthermore, previous a priori simulations of the recent column experiments were based on a model-predicted $\mathrm{K}_{d}$ (i.e., without any dilution factor), which resulted in excellent predictions of the experimental column data (See WSRC-TR-98-00344, Rev. 0). Thus, based on these data and observations the updated designs were prepared using equilibrium data from the TAMU powder model without any dilution factor adjustments.

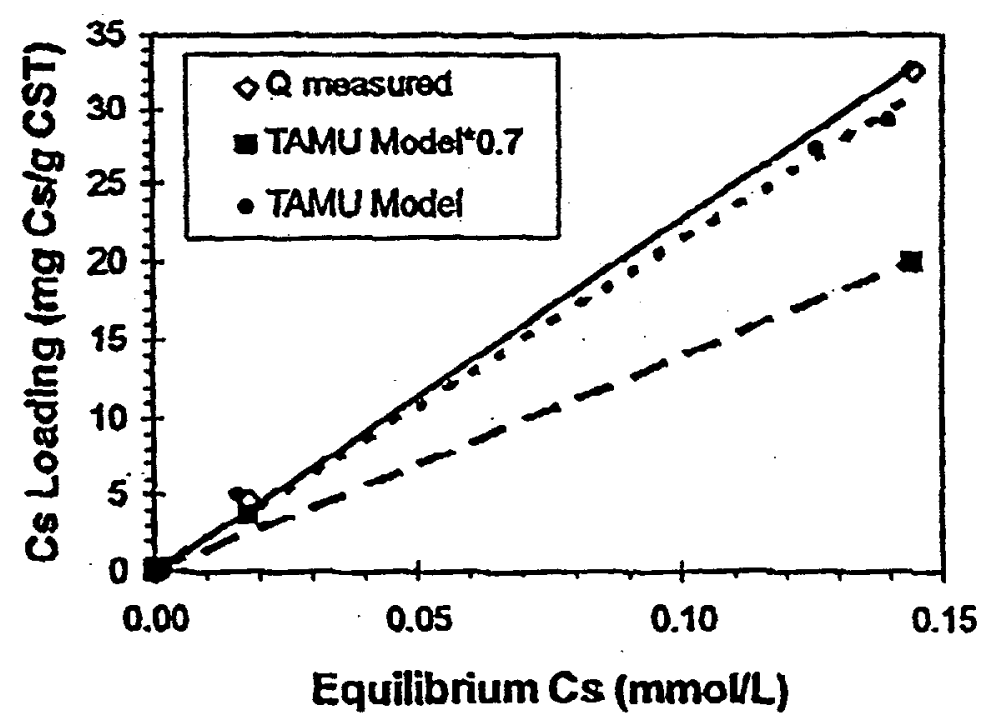

Figure 1. This plot compares experimentally measured equilibrium data for the SRS Average waste with predicted data from the TAMU equilibrium powder model and a model values adjusted by a $70 \%$ dilution factor. 


\section{APPENDIX B (continued)}

\section{Diffusion Coufficient}

Batch kinetic measurements previously conducted at Texas A\&M suggested a diffusion coefficient of $0.27 \times 10^{-10} \mathrm{~m}^{2} / \mathrm{s}$ for the SRS Average waste. Also, this value was used to predict a priori the recent column experiments and provided excellent predictions of the data. The original designs were based upon simulations conducted with the $0.2 \times 10^{-10} \mathrm{~m}^{2} / \mathrm{s}$ for the diffusion coefficient to provide a more conservative design. Based on the recent column data, the estimate for the diffusion coefficient was reevaluated and best-fit, high-limit, and low-limit diffusivities were determined for the SRS Average waste. The best-fit diffusivity was $0.4 \times 10^{-10} \mathrm{~m}^{2} / \mathrm{s}$; the low-limit diffusivity was $0.25 \times 10^{-10} \mathrm{~m}^{2} / \mathrm{s}$; and the high-limit diffusivity was $0.6 \times 10^{-10} \mathrm{~m}^{2} / \mathrm{s}$. Model simulations were conducted for each experiment at these three different effective diffusivities.

\section{Modeling Methods and Results}

Three column experiments were conducted at WSRTC using the Average SRS waste at flow rates of $1.6 \mathrm{CV} / \mathrm{h}$ (slow: $0.27 \mathrm{~cm} / \mathrm{min}$ ), $5.8 \mathrm{CV} / \mathrm{h}$ (intermediate: $0.98 \mathrm{~cm} / \mathrm{min}$ ), and $22.1 \mathrm{CV} / \mathrm{h}$ (fast: $4.1 \mathrm{~cm} / \mathrm{min}$ ). The experimental data were plotted with model simulations using the equilibrium isotherms determined from the TAMO powder equilibrium model and diffusivities of $0.25,0.4$ and $0.6 \times 10^{-10} \mathrm{~m}^{2} / \mathrm{s}$. The figures below show the data overlaid with simulations at these three effective diffusivities. Figure 2 shows the "intermediate" rate $(5.8 \mathrm{CV} / \mathrm{h})$ column experimental data and the three simulations. The best-fit, high-limit and low-limit diffusivities were determined for this "intermediate" experiment and then applied to the other simulations. From the data it is clear that the low-limit value $\left(0.25 \times 10^{-10} \mathrm{~m}^{2} / \mathrm{s}\right)$ provides for a conservative estimate of column breakthrough. Furthermore, the model simulations predict the solid capacity accurately using the equilibrium isotherm generated from the TAMU powder equilibrium model.

Figure 3 shows the "fast" rate (22.1 CV/h) experiment with the corresponding model simulations. Again, the simulations for the three diffusivities are plotted along with the experimental data. Here the model predicts a solid loading approximately $30 \%$ greater than that indicated by the data. The equilibrium isotherm was the same as used for the "intermediate" nun and generated from the TAMU powder model. This equilibrium model has accurately predicted 
APPENDIX B (continued)

isotherms for IE-911 in SRS Average waste as indicated in section 2 above. Furthermore, this model-generated isotherm accurately predicted loading for the "intermediate" run as shown in Figure 2. It should also be noted that the solid loading indicated from the experimental column data of both the "intermediate" and "fast" column experiments differ by about $30 \%$. The equilibrium capacity is only a function of the simulant composition, feod concentration, and column temperature, which apparently do not differ significantly between these two experiments. Thus, the equilibrium loading for both experiments should be very similar. Hence, it is unclear as to why these discrepancies in Cs loading are indicated by the data. Possible reasons for the differences may lie in differences in the experimental procedure, the amount of CST actually loaded into each column, the composition of the simulants, or differences in the IE-911 granules used. Figure 4 shows a plot of experimental data from the "fast" nun and a simulation with an effective diffusivity of $0.4 \times 10^{-10} \mathrm{~m}^{2} / \mathrm{s}$ in which the isotherm was adjusted by $30 \%$. This adjustment allowed for an excellent fit of the data and further indicates that the reason for the discrepancy in the initial simulation probably lies in the capacity of the two columns.

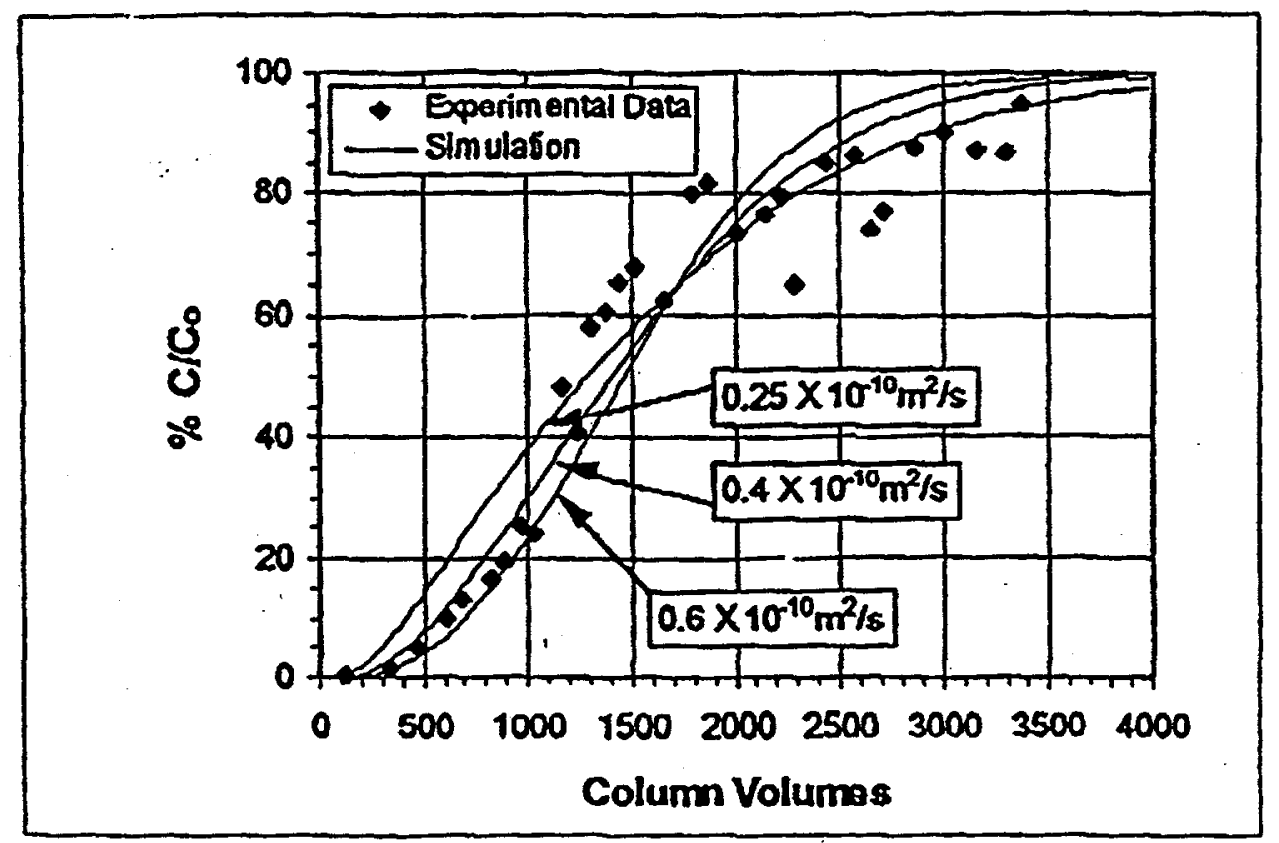

Figure 2. Experimental data for the "intermediate" nun at $5.8 \mathrm{CV} / \mathrm{h}$ and model simulations at effective diffusivities of $0.25,0.4$ and $0.6 \times 10^{-10} \mathrm{~m}^{2} / \mathrm{s}$. 
APPENDIX B (continued)

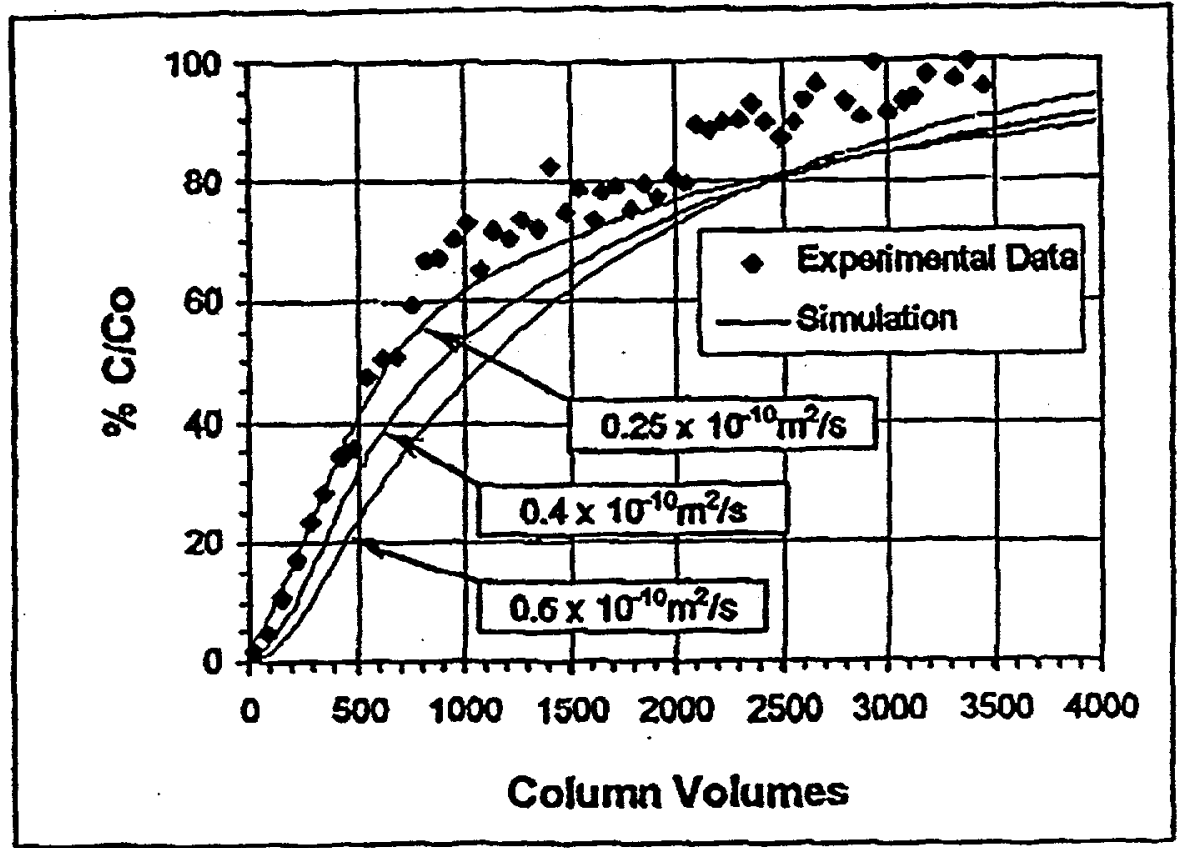

Figure 3. Experimental data for the "fast" nun at $22.1 \mathrm{CV} / \mathrm{h}$ and model simulations at effective diffusivities of $0.25,0.4$ and $0.6 \times 10^{-20} \mathrm{~m}^{2} / \mathrm{s}$.

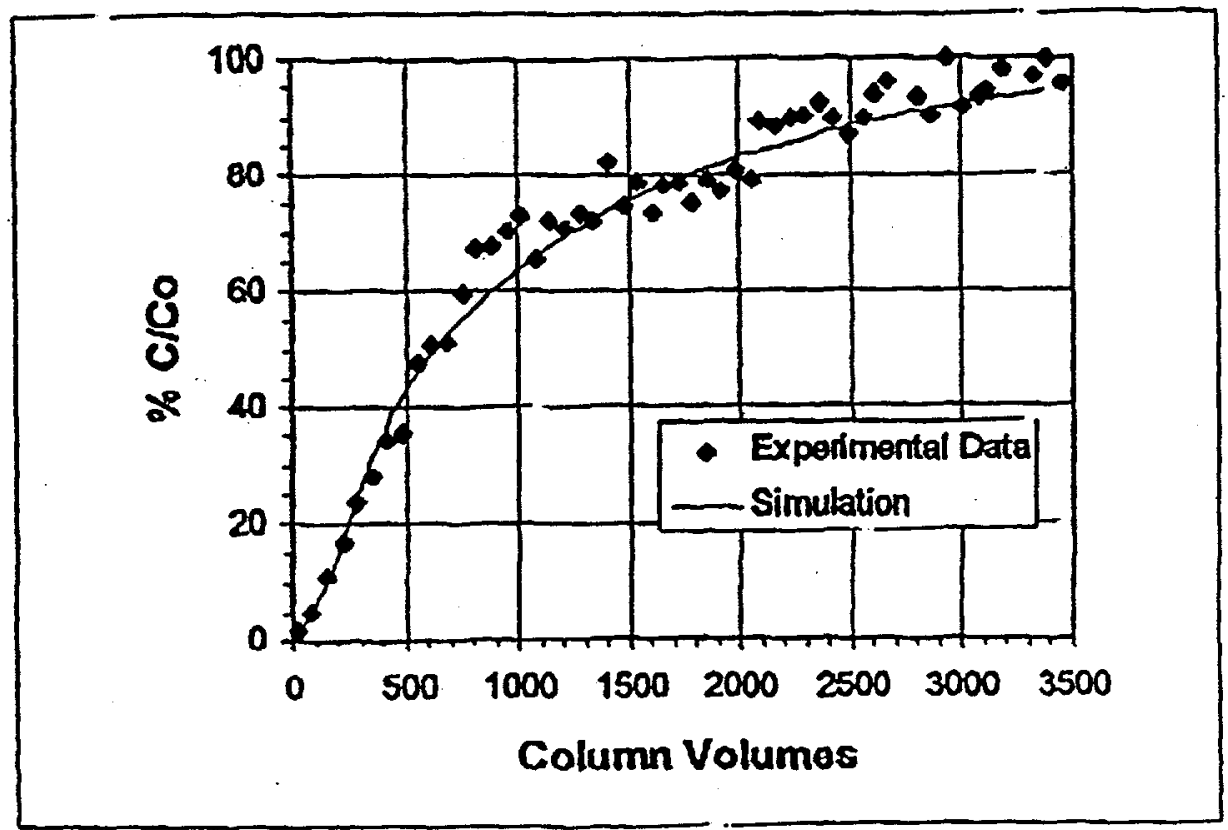

Figure 4. Experimental data for the "fast" run at $22.1 \mathrm{CV} / \mathrm{h}$ and model simulation at effective diffusivity of $0.4 \times 10^{-10} \mathrm{~m}^{2} / \mathrm{s}$ and model-generated isotherm adjusted by $30 \%$. 


\section{APPENDIX B (continued)}

Figure 5 shows the experimental data and model simulations for the "slow" (1.6 CV/h) column run. This plot shows the early part of the breakthrough curve since the experiment was discontinued at a relative effluent concentration of $4.5 \%$. The simulation at $0.6 \times 10^{-10} \mathrm{~m}^{2} / \mathrm{s}$ appears to predict the experimental data well. The best-fit diffusivity indicates a conservative estimate for the breakthrough point. It should be noted that the two-phase homogeneous model usually predicts carly brealthrough for the IE-911 granules as indicated from past experience.

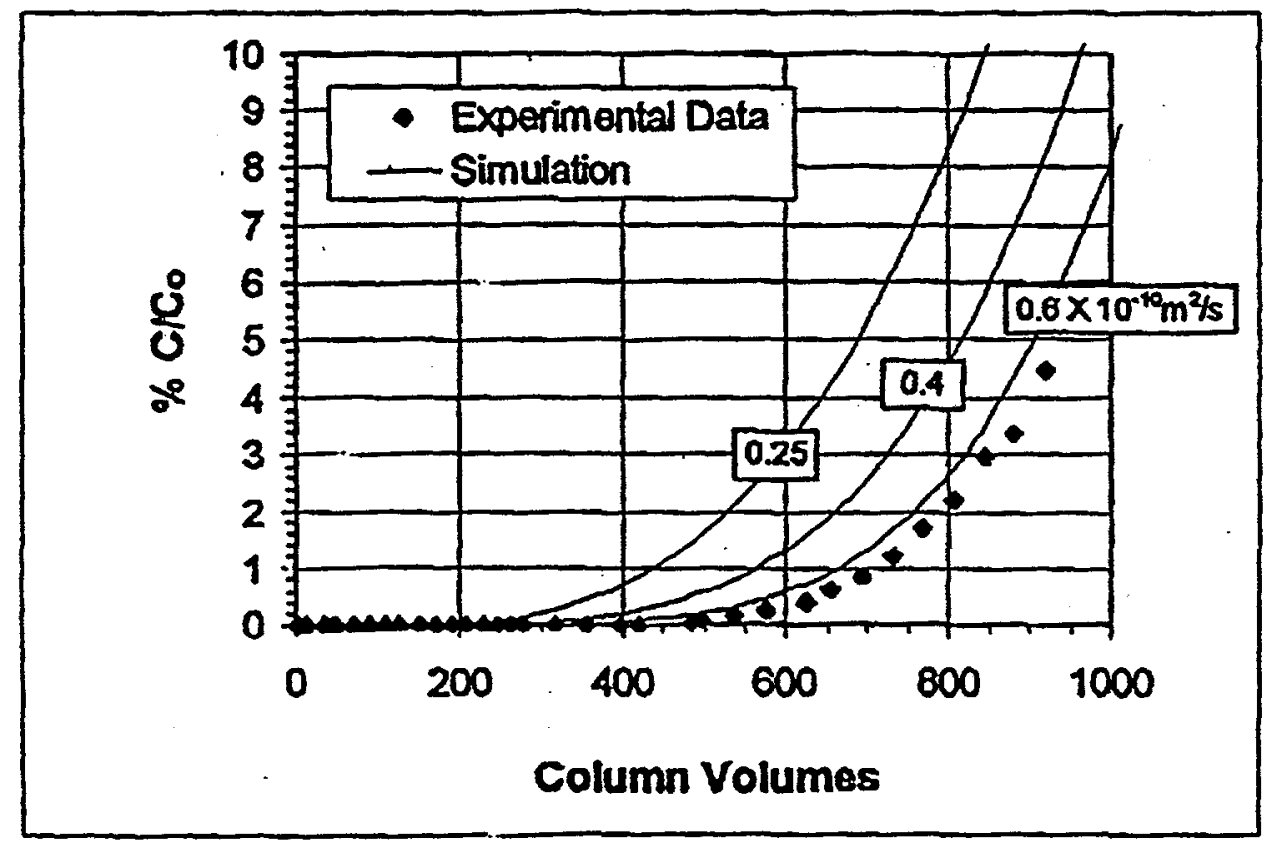

Figure 5. Experimental data for the "slow" run at $1.6 \mathrm{CV} / \mathrm{h}$ and model simulations at effective diffusivities of $0.25,0.4$ and $0.6 \times 10^{-20} \mathrm{~m}^{2} / \mathrm{s}$. 


\section{APPENDIX B (continued)}

\section{Design Case Results.}

The rosults for the SRS design casos are given below. The designs were based on a two-column carousel system with no parallel trains. The effective diffusivity was estimated from recent bench-scale column experiments as $0.4 \times 10^{-10} \mathrm{~m}^{2} / \mathrm{s}$ with an upper and lower limit of $0.6 \times 10^{\circ}$ ${ }^{10} \mathrm{~m}^{2} / \mathrm{s}$ and $0.25 \times 10^{-10} \mathrm{~m}^{2} / \mathrm{s}$, respoctively. The cquilibrium parameters were estimated for a Langmuir isotherm using the TAMU equilibrium powder model predictions without any dilution factor.

Table 1 summarizes the results for the three nominal waste compositions at the three effective diffusivities. Table 2 shows the previous design results, which were prepared using an effective diffusivity of $0.2 \times 10^{-10} \mathrm{~m}^{2} / \mathrm{s}$ and a dilution factor of 0.7 for the equilibrium isotherm.

Figure 6 shows the required carousel volumes for a flow rate of $25 \mathrm{gpm}$. The required volume for a flow rate of $15 \mathrm{gpm}$ is $60 \%$ of the volume for $25 \mathrm{gpm}$. Figure 7 shows the interval time for the column switches for each of the three simulants.

The discrepancy in the apparent capacities between the "fast" and "intermediate" column experiments introduces some uncertainty in the estimated effective diffusivity. Thus, for design purposes we recommend using the low limit diffusivity of $0.25 \times 10^{-10} \mathrm{~m}^{2} / \mathrm{s}$.

Table 1. Design results for fixed column diameter (4 ft) for a two-column carousel with no parallel trains. Lengths are for individual columns and space velocities are based on total carousel volume.

\begin{tabular}{|c|c|c|c|c|c|}
\hline Waste & $\begin{array}{c}\mathrm{D}_{\text {enf }}\left(\mathrm{m}^{2} / \mathrm{s} \mathrm{s}\right) \\
\times 10^{-10}\end{array}$ & $\begin{array}{c}\text { Length } \\
\text { per col (ft) }\end{array}$ & $\begin{array}{c}\text { Volume } \\
\text { Carousel } \\
\left(\mathrm{f}^{3}\right)\end{array}$ & $\begin{array}{c}\mathrm{SV} \\
\left(\mathrm{h}^{-1}\right)\end{array}$ & $\begin{array}{c}\text { Interval } \\
\text { Time(h) }\end{array}$ \\
\hline AVG & 0.4 & 13.9 & 350 & 0.57 & 1308 \\
\hline HiOH & 0.4 & 6.45 & 162 & 1.24 & 408 \\
\hline HiNO & 0.4 & 15.9 & 400 & 0.50 & 1340 \\
\hline AVG & 0.6 & 9.61 & 242 & 0.83 & 903 \\
\hline HiOH & 0.6 & 4.48 & 113 & 1.78 & 283 \\
\hline HiNO & 0.6 & 10.9 & 273 & 0.73 & 918 \\
\hline AVG & 0.25 & 21.9 & 551 & 0.36 & 2060 \\
\hline HiOH & 0.25 & 9.96 & 250 & 0.80 & 630 \\
\hline HiNO & 0.25 & 24.9 & 627 & 0.32 & 2104 \\
\hline
\end{tabular}


WSRC-TR-98-00396 Rev.0

Page 36 of 39

APPENDIX B (continued)

Table 2. Comparison of previous design results for the two-column carousel using dilution factors 0.7 and 1.0.

\begin{tabular}{|c|c|c|c|c|c|c|}
\hline Waste & $\begin{array}{c}\mathrm{D}_{\text {enf }}\left(\mathrm{m}^{2} / \mathrm{s}\right) \\
\times 10^{-10}\end{array}$ & $\begin{array}{c}\text { Dilution } \\
\text { Factor }\end{array}$ & $\begin{array}{c}\text { Length } \\
\text { per col }(\mathrm{ft})\end{array}$ & $\begin{array}{c}\text { Volume } \\
\text { Carousel } \\
\left(\mathrm{f}^{3}\right)\end{array}$ & $\begin{array}{c}\mathrm{SV} \\
\left(\mathrm{h}^{-1}\right)\end{array}$ & $\begin{array}{c}\text { Interval } \\
\text { Time }(\mathrm{h})\end{array}$ \\
\hline AVG & 0.2 & 0.7 & 27.2 & 686 & 0.29 & 1750 \\
\hline HiOH & 0.2 & 0.7 & 12.3 & 312 & 0.65 & 550 \\
\hline HiNO & 0.2 & 0.7 & 31.0 & 780 & 0.26 & 1825 \\
\hline AVG & 0.2 & 1.0 & 27.2 & 686 & 0.29 & 2500 \\
\hline HiOH & 0.2 & 1.0 & 12.4 & 315 & 0.64 & 786 \\
\hline HiNO & 0.2 & 1.0 & 31.0 & 780 & 0.26 & 2592 \\
\hline
\end{tabular}

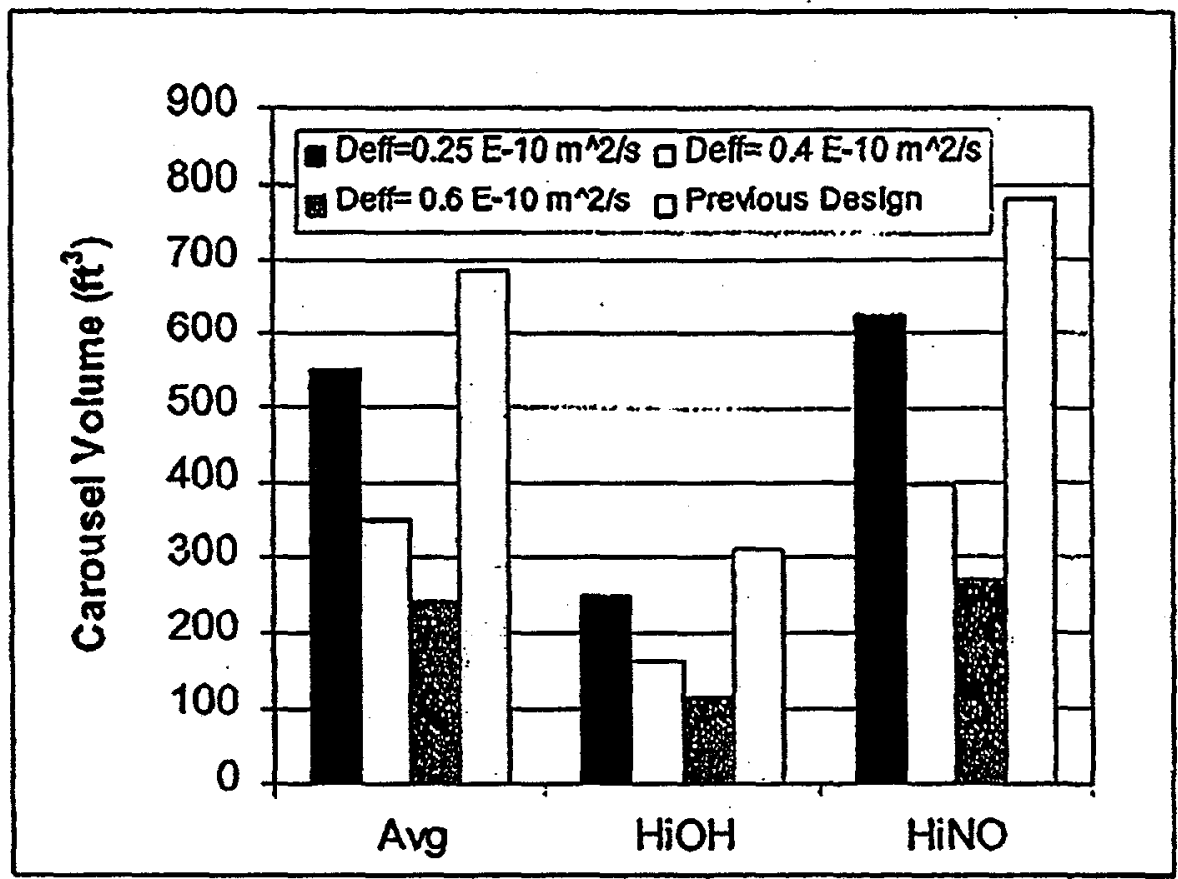

Figure 6. Total volumes for the two-column carousel system for treating SRS waste at $25 \mathrm{gpm}$. Since the required space velocity does not depend on the flow rate, the volumes required at 15 gpm are $60 \%$ of the volumes shown in this figure. The previous design values are shown for the $70 \%$ dilution factor case. 


\section{APPENDIX B (continued)}

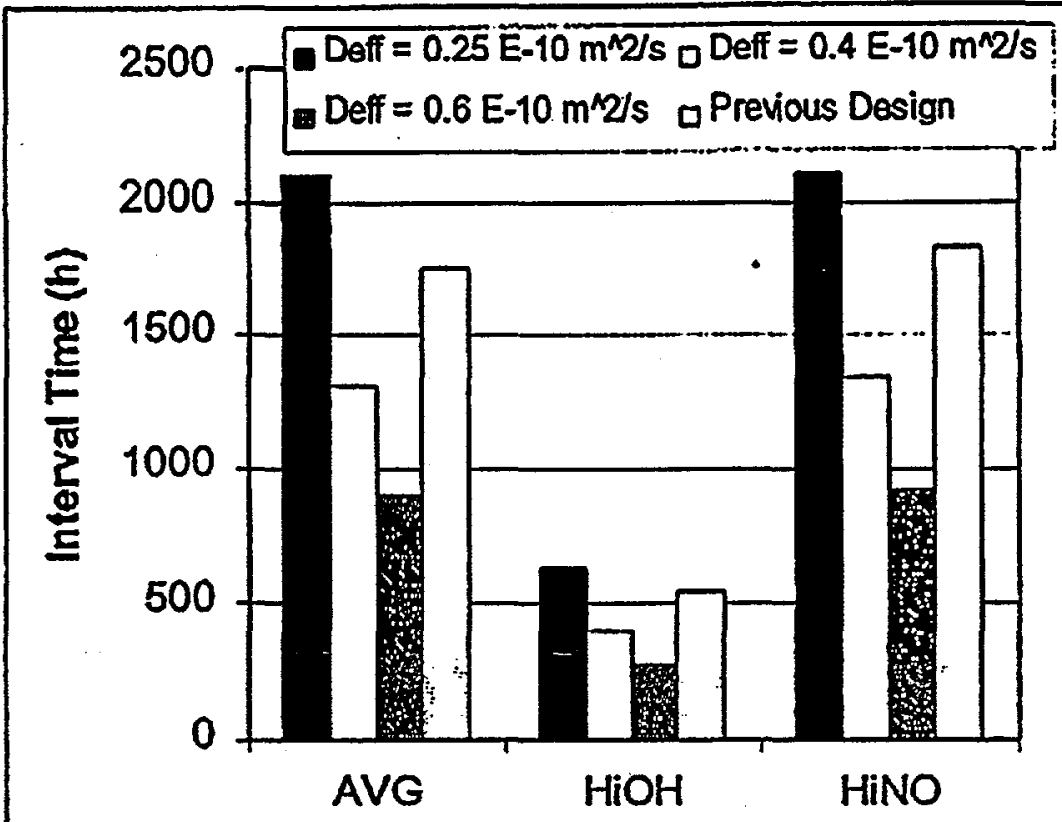

Figure 7. Comparison of the column switch intervals for the design cases considered in this report for the two-column carousel to treat SRS waste. The previous design values are shown for the $70 \%$ dilution factor case. 


\section{APPENDIX B (continued)}

\section{APPENDEX A}

This appendix is included to illustrate and highlight the effect of the different values of the effective diffusivities on the early portion of the breakthrough curves. Figures A-1 and A-2 are for the "intermediate" and "fast" rates column experiments. Figure A-3 illustrates the column experiments and simulations for the "slow" rate experiments. These plots are semi-log plots instead of the log-probability plots customarily used, however, they are very simliar and allow extrapolations. One particular feature that all three curves illustrate is the significant change in the slope in the range of $0.01 \%$ and $0.1 \%$ breakthrough. Therefore, extrapolation of the curves is filled with perils of potential significant error. The second feature to notice is the model predicts breakthrough prior to the experimental breakthroughs. This is particularly apparent for the "slow" rate column experiment.

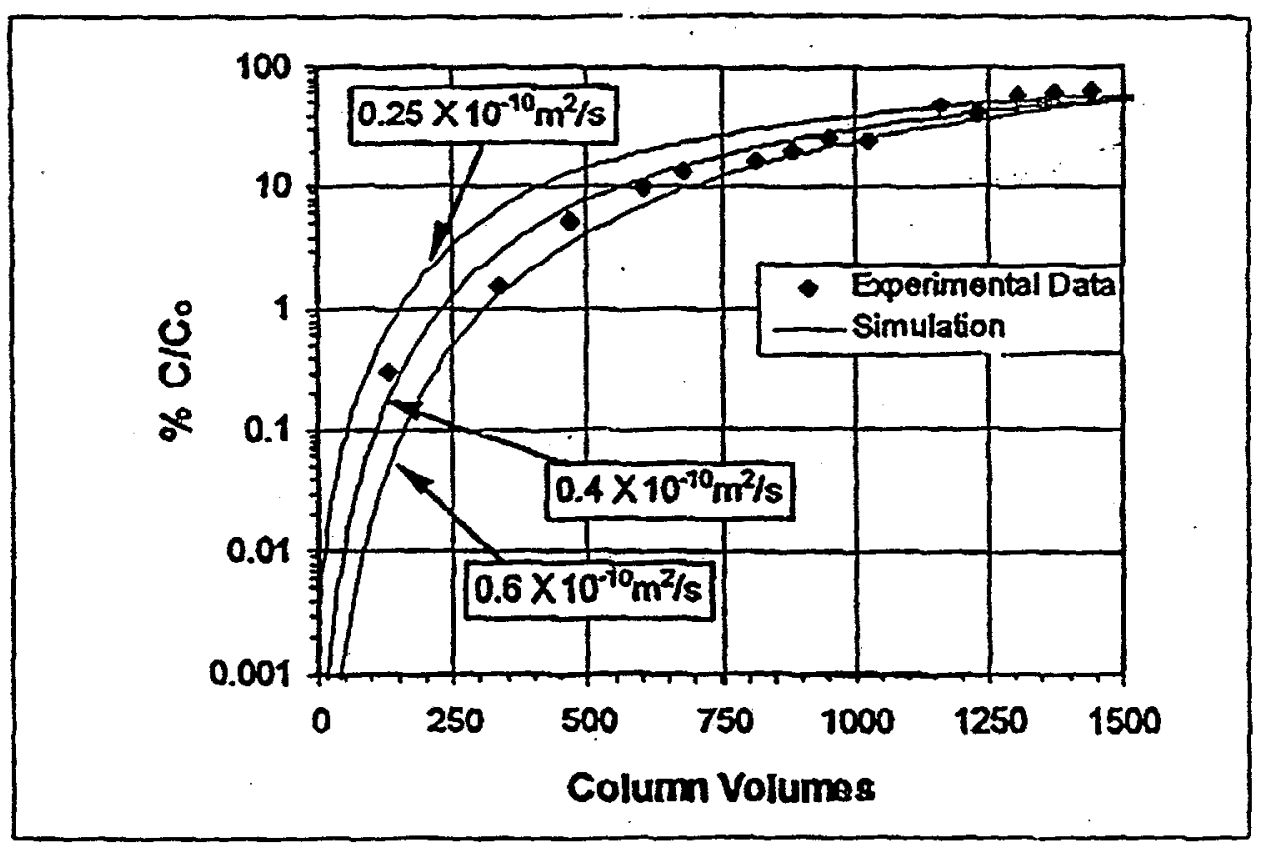

Figure A.1. Semi-log plot of experimental data and model simulations for the "intcrmediate" rate column experiment with SRS Average waste. 
CC: G. E. Abell, 704-3N J. L. Barnes, 704-3N M. J. Barnes, 773-A S. B. Beck, 704-3N N. E. Bibler, 773-A J. D. Carlson, 703-H J. T. Carter, 704-25S G. L. Cauthen, 241-119H W. C. Clark, 704-56H C. L. Crawford, 773-41A Dr. E. Cussler, 704-3N N. R. Davis, 703-H R. A. Dimenna, 773-42A L. O. Dworjanyn, 779-2A R. E. Eibling, 704-T

H. H. Elder, 704-S

S. D. Fink, 773-A F. F. Fondeur, 773-62A

J. R. Fowler, 704-3N

M. W. Geeting, 773-24A

T. Hang, 773-42A

D. T. Hobbs, 773-A

E. W. Holtzscheiter, 773-A

P. I. Hudson, 704-3N

R. A. Jacobs, 704-3N

M. D. Johnson, 703-H

M. T. Keefer, $241-153 \mathrm{H}$

P. S. Kirkland, 703-46A

E. J. Kosiancic, 704-3N

L. F. Landon, 704-T

B. L. Lewis, 703-H
T. J. Lex, 703-H

P. E. Lowe, 773-41A

D. J. McCabe, 773-42A

J. W. McCollough, 703-H

M. S. Miller, 704-56H

T. M. Monahon, 703-H

J. P. Morin, 703-H

E. T. Murphy, 704-3N

C. A. Nash, 773-42A

L. M. Nelson, 773-43A

L. M. Papouchado, 773-A

P. K. Paul, 773-42A

R. A. Peterson, 773-A

S. F. Piccolo, 704-3N

M. R. Poirier, 676-T

K. J. Rueter, 706-S

P. L. Rutland, 704-196N

R. H. Spires, 703-H

W. E. Stevens, 773-A

P. C. Suggs, 704-3N

R. F. Swingle, 773-A

W. L. Tamosaitis, 773-A

G. A. Taylor, 704-196N

W. B. VanPelt, 676-1T

D. D. Walker, 773-A

Dr. J. Watson, 704-3N

W. R. Wilmarth, 773-42A

G. T. Wright, 773-A

TIM, 703-43A

WPTS Files, 773-A, c/o C.C.Canada, 773-A ITP files, c/o Cathy Smalls, 241-147H 